Universidad de Lima

Facultad de Comunicación

Carrera de Comunicación

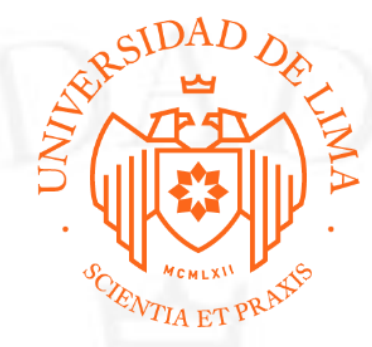

\title{
"PRODUCCIÓN DE BRANDBOOK CON LINEAMIENTOS PARA DISEÑO Y FOTOGRAFÍA DE JOYAS DE MARCA ANIKA"
}

Trabajo de Suficiencia Profesional para optar el grado académico de Licenciada en

\author{
Comunicación
}

\section{Cynthia Annette Mucha Flores}

Código 20130865

\author{
Asesor \\ Miguel Bernal Quijano
}

Lima - Perú 


\section{PRODUCCIÓN DE BRANDBOOK CON LINEAMIENTOS PARA DISEÑO Y FOTOGRAFÍA DE JOYAS DE MARCA ANIKA}




\section{TABLA DE CONTENIDO}

RESUMEN...........................................................................5

INTRODUCCIÓN ............................................................7

CAPÍTULO I: ANTECEDENTES DEL TRABAJO.........................8

1.1. Análisis del macro entorno........................................ 8

1.2. Presentación Marca Anika........................................9

1.3. Público Objetivo.................................................11

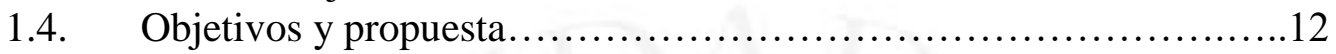

1.5. Referencias................................................ 12

1.6. Análisis de la competencia....................................13

1.6.1. Claudia Navarro.................................................. 13

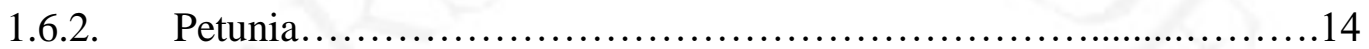

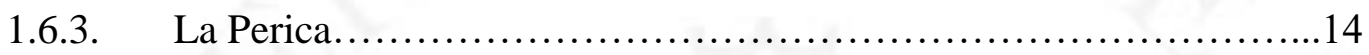

1.6.4. Pandora......................................................... 15

CAPÍTULO II: REALIZACIÓN Y SUSTENTACIÓN..........................16

1.7. Producción fotográfica......................................... 16

1.8. Manual de marca..................................................... 19

1.9. Acciones en Facebook.........................................23

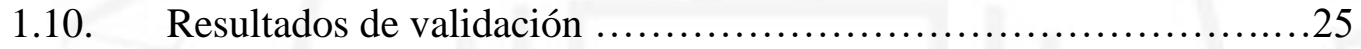

1.10.1. Comentarios de José Contto (Docente)...........................25

1.10.2. Comentarios de Alessandra Baldoceda (Diseñadora gráfico).........25

1.10.3. Comentarios de Angie Ballón (Cliente)............................26

CAPÍTULO III: LECCIONES APRENDIDAS................................27

BIBLIOGRAFÍA....................................................................29

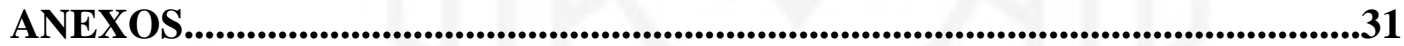




\section{"Dirección web del Brandbook de Anika"}

https://drive.google.com/drive/folders/1POKQ21E59vrKg2J5wLfJxO9nImcsx66G?usp=s

haring 


\section{ÍNDICE DE IMÁGENES}

Imagen 1.1 Aretes mixta Metal martillado con disco de oro $\quad 18$

Imagen 1.2 Collar con dije corazón $\quad 19$

$\begin{array}{ll}\text { Imagen 1.3 Collar con dijes elefante y corazón } & 19\end{array}$

Imagen 1.4 Collar y aretes de plata $\quad 20$

Imagen 1.5 Collar con dije de tortuga $\quad 20$

$\begin{array}{ll}\text { Imagen 1.6 Anillo doble flor } & 21\end{array}$

Imagen 1.7 Isotipo de Anika $\quad 22$

Imagen 1.8 Imagotipo de Anika $\quad 23$

Imagen 1.9 Patrones de Anika $\quad 24$

Imagen 2.1 Portada de Facebook de Anika 25

Imagen 2.2 Ejemplo publicación - Facebook Anika 26 


\section{ÍNDICE DE ANEXOS}

Anexo 1: Branding design Chit Par Jewerly 12

Anexo 2: Behance Lilkin's Handmade Jewerly 12

Anexo 3: Brandbook de Izabel Camille Jewerly 12

Anexo 4: Facebook de Claudia Navarro 13

Anexo 5: Post de Facebook de Claudia Navarro 13

Anexo 6: Página web de Claudia Navarro 13

Anexo 7: Facebook de Petunia 13

Anexo 8: Instagram de Petunia 13

Anexo 9: Página web de inicio de Petunia 13

Anexo 10: Productos en página web de Petunia 13

Anexo 11: Tienda Facebook de La Perica 14

Anexo 12: Facebook de La Perica 14

Anexo 13: Página web de La Perica 14

Anexo 14: Página web de Pandora $\quad 15$

Anexo 15: Post de San Valentín de Pandora 15 


\section{RESUMEN}

En este informe se presenta y sustenta el proceso de elaboración del proyecto "Producción de brandbook con lineamientos para diseño y fotografía de joyas de la marca Anika". Para empezar, se explica el contexto en el que se desarrolla y las oportunidades que tendrían la aplicación y el uso de este trabajo para la comunicación de las redes sociales de la marca. Luego se expone un estudio de cinco joyerías presentes en el Perú y manuales de marca (brandbooks) para generar la propuesta del proyecto. Asimismo, se describe el público objetivo, la personalidad, propósito y promesa de la marca Anika.

En lo que se refiere a la producción del brandbook, se explica el por qué se decidió renovar el imagotipo y los elementos representativos de la marca y cómo, a partir de los cambios, se define un nuevo estilo que refleja la modernidad y versatilidad que persigue Anika.

Finalmente, se describen los objetivos que busca este proyecto junto a la conclusión, analizando el recorrido del trabajo realizado y las lecciones aprendidas del proceso.

Palabras claves: brandbook, lineamientos de marca, joyas, diseño, fotografía 


\begin{abstract}
This document presents and supports the process of elaboration of the project "Production of brandbook with guidelines for design and photography of jewels of the Anika brand". To begin, the context in which it develops and the opportunities that the application and use of this work would have for the communication of the brand's social networks are explained. Then there is a study of five jewerls stores here in Peru and brand manuals that where considered to generate the project proposal. It also describes the target audience, the personality, purpose and promise of the Anika brand.

With regard to the production of the brandbook, it is explained why it was decided to renew the imagotype and the representative elements of the brand and how, from the changes, a new style is defined that reflects the modernity and versatility that Anika pursues.

Finally, the objectives of this project are described along with the conclusion, analyzing the path of the work carried out and the lessons learned from the process.
\end{abstract}

Palabras claves: brandbook, guidelines, jewerly, design, photagraphy 


\section{INTRODUCCIÓN}

Anika es una joyería peruana que produce joyas con diseños únicos y diseñados en conjunto con sus propios clientes. Con el paso de los años, la marca ha venido fortaleciéndose y ampliando su línea de productos y cartera de clientes.

A partir de ello, surge la necesidad de construir una identidad fuerte, alineada al propósito y promesa de la marca con el fin de generar mayor presencia e incrementar sus ventas a través de una estrategia de comunicación. Para iniciar este proceso, el imagotipo ingresa a una etapa de reconstrucción y se incorporan nuevos elementos que sistematizan los lineamientos de diseño y fotografía para luego aplicarlos en las redes sociales de Anika.

Del mismo modo, se realiza una propuesta fotográfica y se incorpora el catálogo de joyas en el que se visualizan todas las piezas de la marca. Este material debe ser publicado en la página oficial de Anika, dentro de la red social Facebook, para que el público encuentre la cartera de productos completa y actualizada.

En resumen, este proyecto se ha realizado para reforzar el posicionamiento de la identidad de la marca mediante la producción del manual de marca o brand book, generando una comunicación integrada en sus redes sociales a través de acciones concretas. 


\section{CAPÍTULO I: ANTECEDENTES DEL TRABAJO}

\subsection{Análisis del macro entorno}

El mercado de joyerías ha evolucionado y crecido exponencialmente a lo largo de los últimos años. Para el 2019, Perú estimó un crecimiento por valor exportado del 17\% respecto al 2018 , logrando un valor comercial cercano a \$148 millones. La industria se encuentra en auge en cuanto a artículos de joyería, metales preciosos, bisutería, etc. se refiere, y entre los principales destinos de exportación Estados Unidos registra una participación del 98\% a septiembre del 2019, teniendo como principales productos de exportación los anillos, collares, pulseras y afines. (Perú Retail, 2019)

Es por ello que, a lo largo de los años, los mercados y productos han variado y se han reacondicionado de la mano de los patrones de comportamiento y de consumo. La mujer peruana ya no es la misma y ha cambiado mucho, más aún desde los albores del nuevo siglo. La progresiva reducción del número de hijos por familia (de cinco a dos, como promedio nacional), ha permitido que hoy en día la mujer tenga más tiempo para estudiar, trabajar y entrar con más fuerza a otros espacios (Arellano, 2019). A partir de ello, los estilos de vida fueron cambiando, como es el caso de las mujeres sofisticadas y modernas que crecieron y trajeron consigo nuevos intereses y hábitos de compra.

Con respecto a la adquisición de compras de joyas, si bien no se ha encontrado información precisa sobre este rubro, se puede observar que, según los Estilos de Vida (EdV) LATIR en el 2017 en Perú y en América Latina, las sofisticadas y modernas prestan mayor atención al cuidado personal y de moda. (Arellano, 2019) 
En el caso de las joyas se pueden considerar productos de compra dentro de la categoría de ocasionales. Esto se debe a que estos productos ofrecen una mayor durabilidad y la decisión de compra es, en ciertos casos, más racional, sin dejar de lado el beneficio emocional y de autoexpresión que esta categoría de productos suele ofrecer.

Al ser un producto ocasional las mujeres suelen tomar en cuenta diversas consideraciones antes de comprarlo como el material, el diseño, la garantía, entre otros. Ellas evalúan que el producto se amolde a su estilo, les hagan sentir únicas y realcen su belleza. (Silvia Cama, comunicación personal, mayo 2019)

Frente a esta información, se analizaron los productos, lineamientos y el estilo de comunicación en las redes sociales de joyerías como Petunia, Tous, La Perica, Claudia Navarro y Pandora; que se dirigen a un público objetivo del NSE AB y cuentan con diversos puntos de venta alrededor de Lima.

Al estar presentes en los centros comerciales o tiendas físicas propias, mantienen un stock de cada una de sus piezas por lo que no poseen modelos únicos. A partir de ello, encontramos una necesidad que Anika, una marca peruana con más de 15 de años en el mercado, satisface.

\subsection{Presentación Marca "Anika"}

En el 2004, Angie Ballón incursiona en el mundo de las joyas con Anika, una empresa dedicada a la belleza femenina mediante el diseño y producción de joyas únicas y de calidad para mujeres que les gusta cuidar su imagen personal y proyectar un propio estilo.

La fundadora de la marca escogió el nombre "Anika" porque luego de testearlo con su grupo de amigas, fue escogido como el nombre más original y con mayor recordación. Para Angie Ballón, Anika significa ser apasionada por su trabajo, original y creativa al proponer nuevas ideas. 
Anika empezó vendiendo collares, aretes, anillos y pulseras de bisutería y con solo ocho modelos producidos en plata, los aretes fueron los productos más solicitados y vendidos. Sus primeras clientas fueron sus propias amigas quienes la llevaron a tener contacto con las empresas donde ellas trabajaban, ampliando su red de contactos. Es así que Anika empieza a desarrollar alianzas con algunos casinos del distrito de San Borja para días festivos, como Día de la Madre, Aniversarios y/o activaciones que programaban para obsequiar a sus clientas más frecuentes.

Con el pasar de los años, Anika se consolidó como marca y empezó a producir pulseras, aretes, anillos, collares en oro, plata, perlas, piedras preciosas, entre otros. Adicionalmente, encontró una nueva oportunidad de mercado y extendió su marca presentando una línea de regalos corporativos como llaveros, placas, retratos, adornos, que eran muy solicitados por las empresas.

En cuanto a su personalidad, Anika se define como una mujer versátil, social e innovadora que busca constantemente ideas y opiniones de sus clientes para crear diseños únicos, forjando una relación cercana y duradera con ellos.

Como su slogan lo dice, Anika busca expresar la esencia, reforzando el concepto de que cada mujer es única. Es así que la esencia de Anika se refleja en la personalización de los productos que diseña según los estilos y preferencias de sus clientas. Otro factor importante que caracteriza a la marca es que se amolda a la capacidad de inversión de sus clientes, ofreciéndoles opciones de materiales similares con un presupuesto más accesible, sin dejar de lado la calidad del producto.

Cabe resaltar que Anika, consiguió una alianza con Florerías Unidas, una florería ubicada en Miraflores. En dicho local tiene instalado un mostrador donde exhibe sus joyas y genera alianzas con la florería para ocasiones especiales como el día de San Valentín, Día de la Mujer, Día de la Madre o Navidad, entre otros. 
A pesar de contar con un espacio físico, realiza ventas desde sus plataformas sociales como whatsapp y su página de Facebook, que cuenta con más de 600 seguidores. A través de esta red social, Anika publica sus colecciones por temporada y mantiene contacto con sus clientes que suelen solicitarle sus productos o servicio de limpieza, reconstrucción, rediseño de joyas propias, entre otros.

\subsection{Público objetivo}

Anika tiene como público objetivo a mujeres entre 25 a 50 años de nivel socioeconómico B,

profesionales y amas de casa que disfrutan de una activa vida social y cuidan su imagen personal.

Según los nuevos estilos de vida, las mujeres modernas se caracterizan por ser versátiles, innovadoras y soñadoras que trabajan o buscan estar constantemente activas a través de estudios, actividades, deportes, disfrutan de ir al cine, parques y centros comerciales y usan marcas como símbolo social y señal de calidad.

Por otro lado, las sofisticadas tienen un nivel de ingreso más alto que el promedio. Son muy modernas, educadas, liberales, cosmopolitas y valoran mucho la imagen personal. Les importa su estatus, prestan más atención a su arreglo personal y a la moda; les gusta relajarse, divertirse y les interesa los nuevos medios de comunicación. (Arellano, 2019)

En ambos casos, mujeres modernas y sofisticadas, valoran la imagen personal por lo que compran artículos que satisfagan esa necesidad. Asimismo, les gusta la moda y consideran a los accesorios como joyas, bisutería, relojes, entre otros, como esenciales acompañamientos de sus prendas de vestir que usan en el día a día para el trabajo, reuniones, eventos y otras ocasiones. 


\subsection{Objetivos y propuesta}

La realización de este proyecto está orientado en reforzar el posicionamiento de la identidad de marca, basándose en los atributos de la misma.

En este caso, Anika busca ser una joyería versátil e innovadora que diseña piezas únicas, cocreadas con los clientes e inspirada en la esencia y personalidad de las mujeres.

Para reforzar el posicionamiento de Anika, le acompañan tres objetivos secundarios:

- Reconstruir el imagotipo y elementos principales, consolidando la identidad de Anika.

- Generar una comunicación integrada de la marca en sus redes sociales a través de una agenda visual.

- Incrementar la presencia de marca a través de una estrategia de comunicación en Facebook.

\subsection{Referencias:}

Para realizar el presente trabajo se consultaron tres manuales de marca de joyerías en las páginas de Behance e Issuu.

Se eligieron los manuales de las joyerías internacionales Izabel Camille, Lilkin's y Chit Par debido a que cada uno tenía características particulares que podían ser adaptados al manual de Anika.

En primer lugar, en el archivo de "Chit Par Jewerly" destacan las imágenes de sus joyas, la diagramación del patrón oficial y la presentación de su pantone. (Anexo 1) Por otro lado, el trabajo de "Lilkin's handmade Jewerly", muestra vistas previas de sus joyas en diversas plataformas sociales y diseñadas sobre mockups; lo singular de este trabajo es que la marca produce piezas con diseños rústicos orientados a la naturaleza y a su vez incorpora en su presentación fondos con elementos con hojas reales formando un contraste interesante. (Anexo 2) 
Por último, el manual de "Izabel Camille Jewelry" es uno de los mejores producidos ya que crea armonía entre las imágenes profesionales y el contenido del trabajo. La tipografía san serif elegida estiliza y resalta la elegancia de la marca y a su vez complementa el cuerpo de texto de cada lámina. La estructura del trabajo pretende parecerse a las revistas de moda por lo que las imágenes juegan un papel importante en cada hoja del manual causando un alto impacto visual.

\subsection{Análisis de la competencia:}

Hoy en día, existen joyerías para diversos públicos y con varios formatos. Es por ello que se han investigado algunas marcas, con productos y precios de venta similares a los de Anika, para comparar atributos, lineamientos y estrategia de comunicación.

Asimismo, se han incluido otras joyerías de alta gama que, si bien no son una competencia directa ya que se enfocan en un público objetivo con mayor poder adquisitivo, son importantes para conocer qué tipos de productos venden y cómo manejan sus plataformas digitales.

\subsubsection{Claudia Navarro}

Claudia Navarro (https://claudianavarro.com/pages/about-us) es una marca peruana que cree que la joyería además de ser hermosa, debe de hablar y transmitir significados. Describe sus joyas como simples, modernas y delicadas, inspiradas por la belleza de un espíritu libre y natural.

Con más de 70000 seguidores en su página de Facebook (Anexo 4), esta marca publica su material fotográfico de calidad con una paleta de colores pasteles análogos y complementarios al imagotipo de la marca. Su estilo de comunicación se caracteriza por incluir frases positivas, mensajes de superación y buenos deseos. 
Sus últimos posts publicados celebran una fecha festiva y agregan frases alusivas a encontrar el regalo perfecto seguido del link de su página web. (Anexo 5) En este último, exhibe todos sus productos en formato catálogo con una descripción correspondiente (Anexo 6).

Claudia Navarro es una marca consolidada que exporta nacionalmente e internacionalmente sus joyas, trabajando con un stock definido por modelo.

\subsubsection{Petunia}

Petunia (https://www.facebook.com/Petunia.com.pe/) es una marca que vende joyas, bijouterie y accesorios hechos a mano para mujeres y niñas en oro, plata, plata bañada en oro, entre otros. "Toda reina merece tener corona", es el slogan de la marca y hace referencia a su elemento representativo: la corona.

Utiliza sus redes de Facebook e Instagram para mostrar sus joyas puestas en modelos y sobre tela de colores pasteles, en su mayoría rosados (Anexo 7 y 8). Por otro lado, en su página web organiza sus productos por categoría y el material fotográfico que utiliza varía en fondo blanco, con modelo, con empaque, entre otros (Anexo 9).

Asimismo, en cada producto agrega una descripción y se visualiza una opción de "consultar a whatsapp" que te redirecciona a un chat para hacer las consultas del producto y/o comprarlo. (Anexo 10)

\subsubsection{La Perica}

La Perica (https://www.facebook.com/pg/lapericajoyas/shop) es una Joyería artesanal (hecho a mano) donde se combinan piedras naturales, muranos, accesorios en acero, cobre, plata pura y plata enchapada en oro. (Anexo 11).

La Perica se describe como: "... un grupo de mujeres artesanas y diseñadoras, inspiradas en crear piezas tan versátiles que puedan ser usadas por todo tipo de mujer." (Anexo 12). La marca cuenta con seis módulos de venta en Lima y uno en provincias, además de su propia tienda online en su página web; sus precios se encuentran entre el rango de S/.20 a S/.200. 
Luego de revisar su página web, se aprecia que cuenta con productos hechos de plata, oro e hilos trabajados a mano. También incluye accesorios como holder de lentes y tobilleras. Además, existe una sección de colecciones según el material con el que trabaja (silver gold, rose gold, plata pura, bebé, religiosa). Su última colección está relacionada al verano y al mar, muy similar a una colección de una marca descrita previamente.

En cuanto a su presentación y empaque, los productos se entregan en una bolsa sobre un papel cartulina con un mensaje impreso. (Anexo 13)

\subsubsection{Pandora}

Pandora (https://www.pandora.net/es-pe) es un fabricante danés de joyas fundado en 1982, presente en más de 55 países. Su imagotipo lleva el nombre de la marca y una pequeña corona sobre la letra "O" formando el ícono de un anillo.

Pandora se define como una joyería que está pensada para que puedas crear y combinar. Poseen una gran variedad de charms, pulseras, anillos, pendientes, collares, colgantes y relojes que expresan el estilo personal de cada mujer. Asimismo, resalta que cada detalle de sus piezas es considerado cuidadosamente antes de pasar a manos de sus orfebres, usando oro de $14 \mathrm{k}$ y de $18 \mathrm{k}$, plata de ley y gemas seleccionadas, piedras y perlas cultivadas combinando técnicas centenarias y un diseño moderno para dar lugar a hermosos diseños. (Pandora, Facebook, 2020)

En su página web se puede encontrar todos los productos y colecciones de la marca y también una sección llamada "Universo" donde se encuentra una guía de joyas, el proceso de producción, mantenimiento de una joyas, entre otros. Esto es algo nuevo en relación a las otras marcas, en el cual contiene información relevante para sus clientes. (Anexo 14)

El facebook oficial de Pandora Perú, hace publicaciones continuas de fotos y videos de sus productos o campañas vigentes. En sus imágenes y videos muestran a grupos de mujeres, parejas, madres e hijos entre otros en actividades del día a día, así como también publican las piezas editadas sobre un fondo rosado. (Anexo 15) 


\section{CAPÍTULO II: REALIZACIÓN Y SUSTENTACIÓN}

\subsection{Producción fotográfica}

\section{Sesiones fotográficas para joyas}

Luego de desarrollar el análisis de referencias de catálogos de joyas y accesorios de mujer, se revisó toda la cartera de productos de Anika y se entrevistó a la clienta para conocer los intereses y expectativas de la marca con el fin de proponer una temática para las sesiones fotográficas.

Imagen 1.1 Aretes mixta Metal martillado con disco de oro

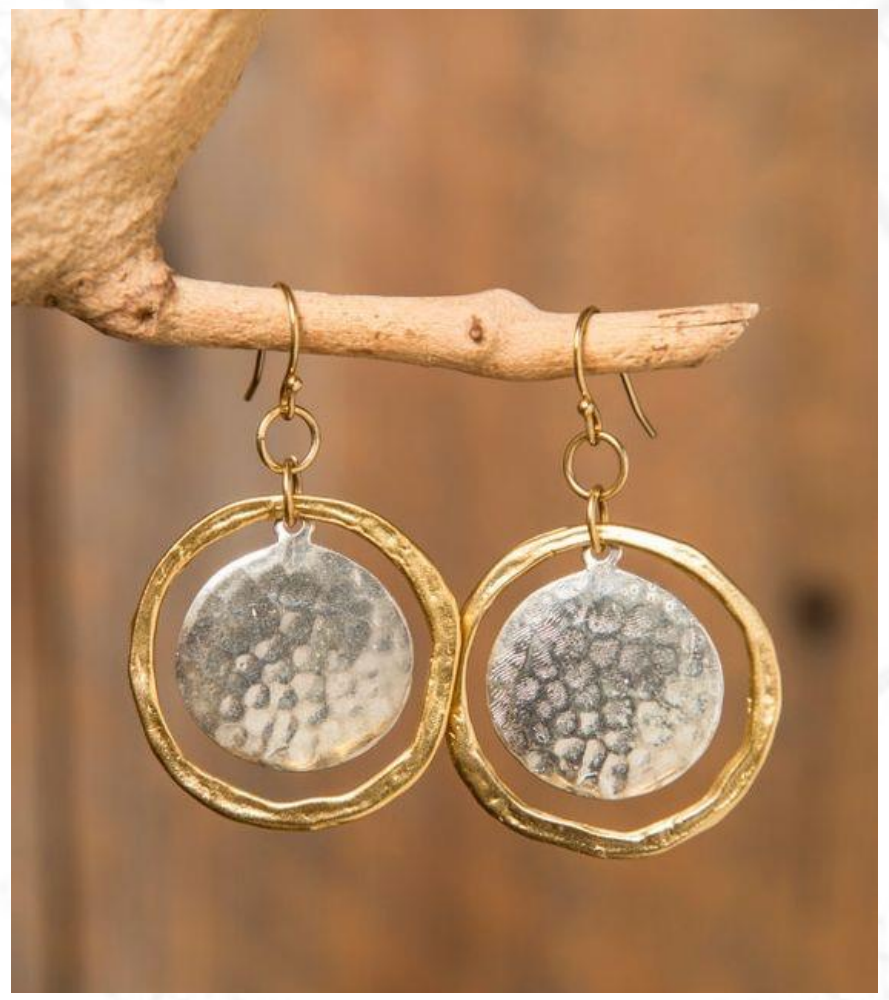

Fuente: Etsy (2019)

En base a las propuestas presentadas al cliente, se decidió realizar las sesiones fotográficas en un ambiente natural, haciendo uso de árboles, ramas, troncos, anillos de crecimiento, luz natural y otros elementos que permitieron generar un contraste de matices con las joyas, resaltando la belleza y características propias de estos elementos. 
La primera sesión se desarrolló a fines del 2017. Durante estas, se usó un lente teleobjetivo para conseguir detalles de las texturas de las joyas en el entorno natural descrito previamente. En algunas tomas, se utilizó el desenfoque para posicionar la joya en un primer plano gracias al efecto bokeh, como se aprecia en la imagen a continuación.

Imagen 1.2 Collar dije corazón

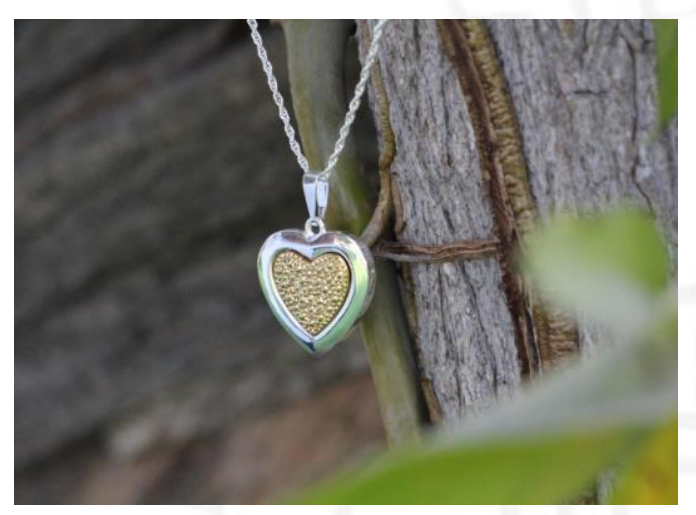

Imagen 1.3 Collar dijes elefante y corazón

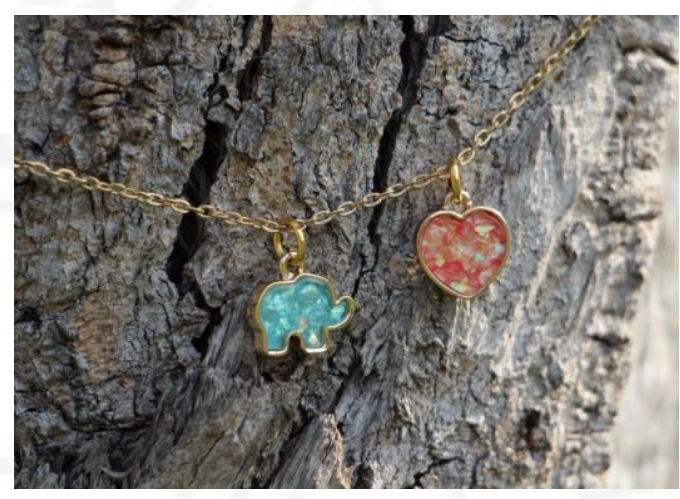

Fuente: Elaboración Propia

El proceso continuó con la elección de imágenes del material fotográfico obtenido para pasar a la fase de postproducción en Adobe Photoshop. En esta etapa se realizaron retoques, efectos de iluminación, ajuste de color y modificaciones de tamaño. Este proceso se produjo continuamente debido a la incorporación de nuevas joyas. 
Con el paso del tiempo, se recibieron sugerencias de técnicas y producción de arte donde se planteó tener una ambientación propia de la naturaleza junto a otros elementos representativos como troncos de madera, hojas y flores artificiales. Con respecto a la técnica, las joyas fueron fotografiadas con un encuadre más cerrado para observar con mayor detalle el tallado y construcción de la joya.

En aquellas fotografías grupales, es decir, donde compartían escena collar, aretes o pulseras del mismo modelo, se optó por tomas abiertas con elementos superpuestos. Todas las piezas fotográficas se trabajaron con luz natural y un rebotador para equilibrar la incidencia de luz.

Imagen 1.4 Collar y aretes de plata

Imagen 1.5 Collar con dije de tortuga
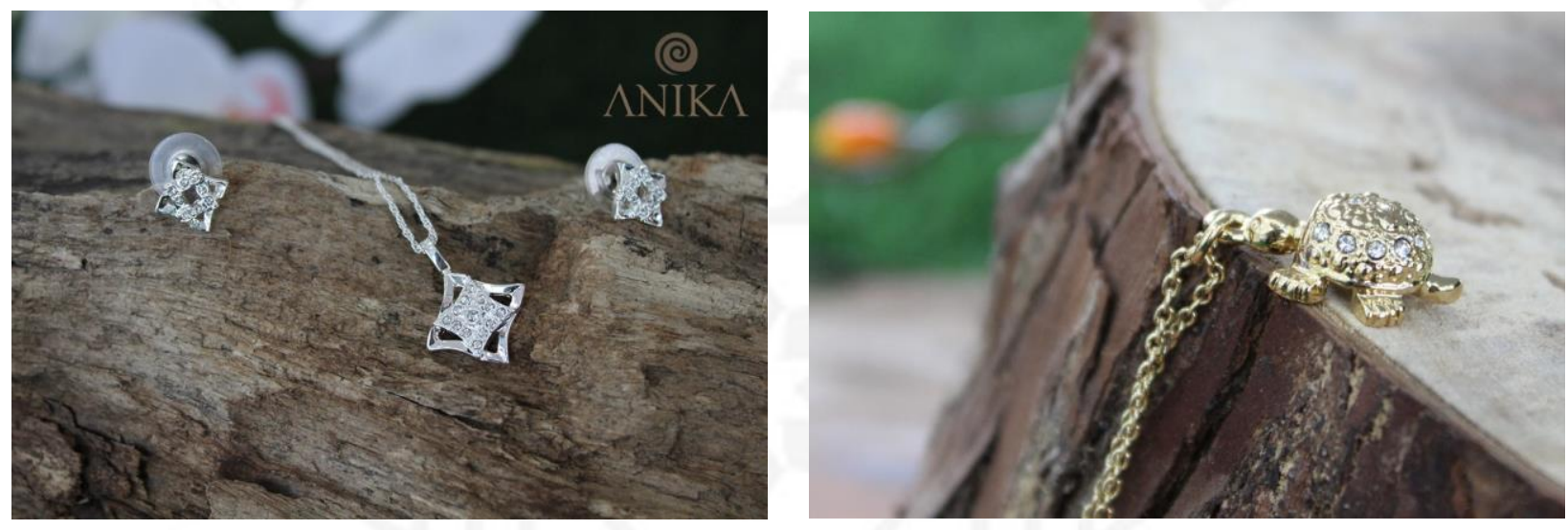

Fuente: Elaboración Propia

\section{Sesiones fotográficas para catálogo}

Luego de visitar las páginas web de cinco joyerías, se pudo comprobar que todas presentaban las fotos de sus joyas sobre fondos blancos para lograr alto contraste tonal y de texturas. Por esa razón, se optó por armar el catálogo con las joyas en fondo claro de manera que, si los clientes lo solicitaban, Anika podría compartir las imágenes de sus productos. 
Para obtener fotografías en fondo blanco se utilizó una caja blanca acompañada de luces led que no resultaron apropiadas ya que estas proyectaban sombras. Se continuaron las pruebas de iluminación con un LightBox que permitió obtener mejores imágenes.

Imagen 1.6 Anillo doble flor
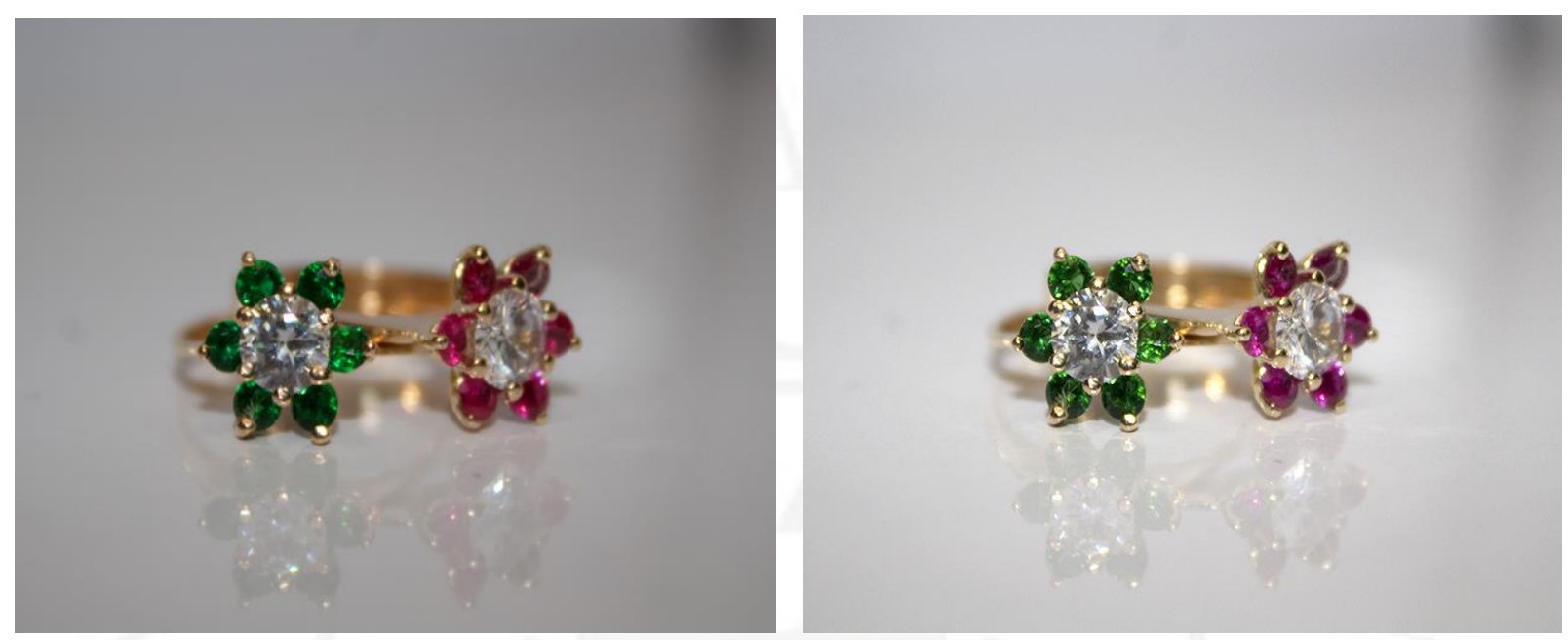

Fuente: Elaboración Propia

Las fotografías tomadas en fondo blanco pasaron a ser retocadas en Adobe Photoshop debido a las diferentes posiciones de los productos e incidencia de luz. Con esta edición, se pudo calibrar la luz y limpiar las imperfecciones del background.

\subsection{Manual de marca}

En esta parte, se presenta la secuencia de acciones realizadas para la construcción del manual de Anika, una vez terminada la etapa de investigación y búsqueda de referencias. 


\section{$\underline{\text { Diseño del brandbook }}$}

En las primeras entrevistas con la clienta se planteó diseñar el manual con una estructura sencilla agregando el espiral representativo de Anika y colores de la marca como elementos fijos en todas las páginas. Sin embargo, luego de armar algunas propuestas, se identificó que lo mencionado anteriormente no concordaba con lo que la marca buscaba representar. Debido a esto, se plasmaron nuevas acciones como la renovación del imagotipo en diseño y significado y se agregaron nuevos elementos de marca.

A su vez, siguiendo el nuevo concepto y personalidad de marca, se diseñó un logotipo con una nueva tipografía, Lato Thin; sin embargo, en esta primera construcción no se incluyó un sistema de proporciones ni una consideración geométrica.

Posteriormente, se retocaron los vectores y la posición del espiral produciendo mejoras en el isotipo. Por otro lado, en el imagotipo se definieron los colores precisos para la impresión en cuatricromía tomando como referencia la paleta de colores que ofrece la compañía Pantone.

Imagen 1.7 Isotipo de Anika

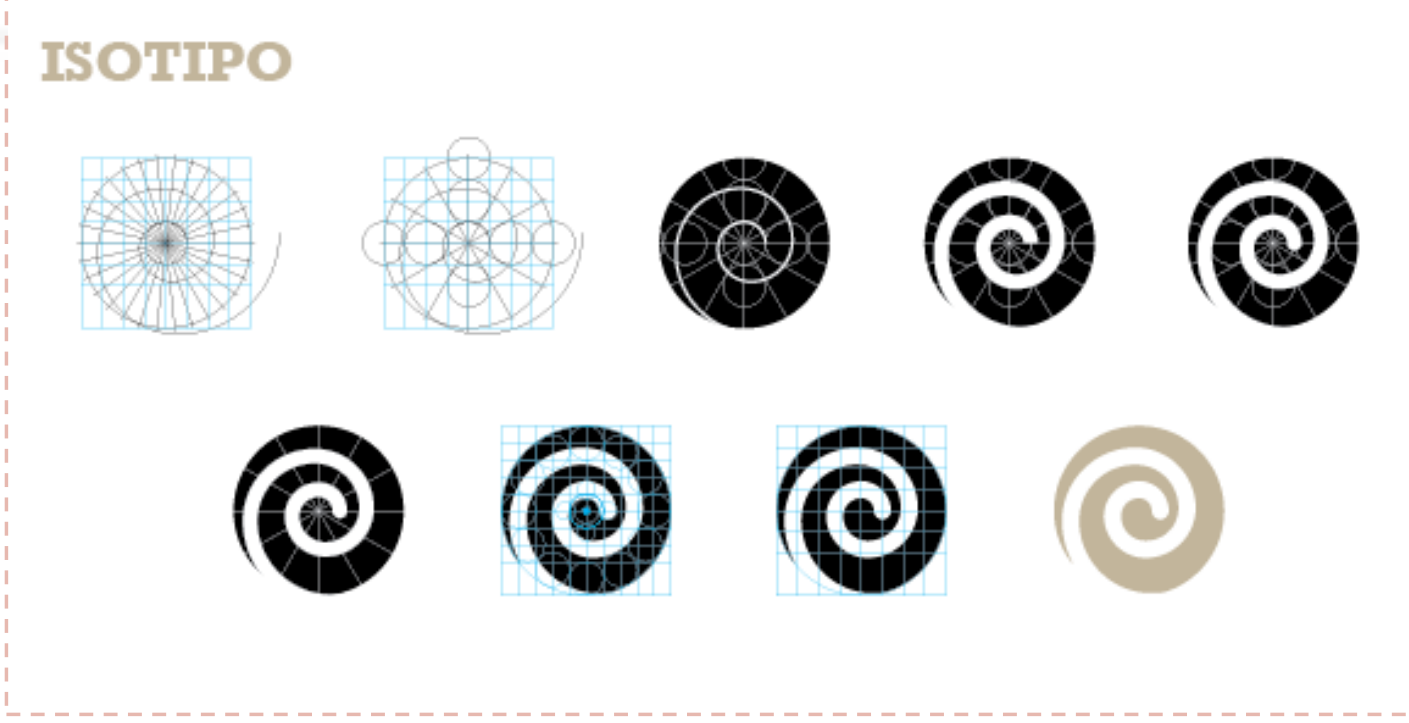

Fuente: Elaboración Propia 
Mediante la aprobación del nuevo imagotipo de Anika, se logró representar la modernidad y versatilidad que caracteriza a la marca. A su vez, se conservó la forma de espiral del isotipo con el fin de representar la originalidad y diversidad de los productos que ofrece la propia marca.

Imagen 1.8 Imagotipo de Anika

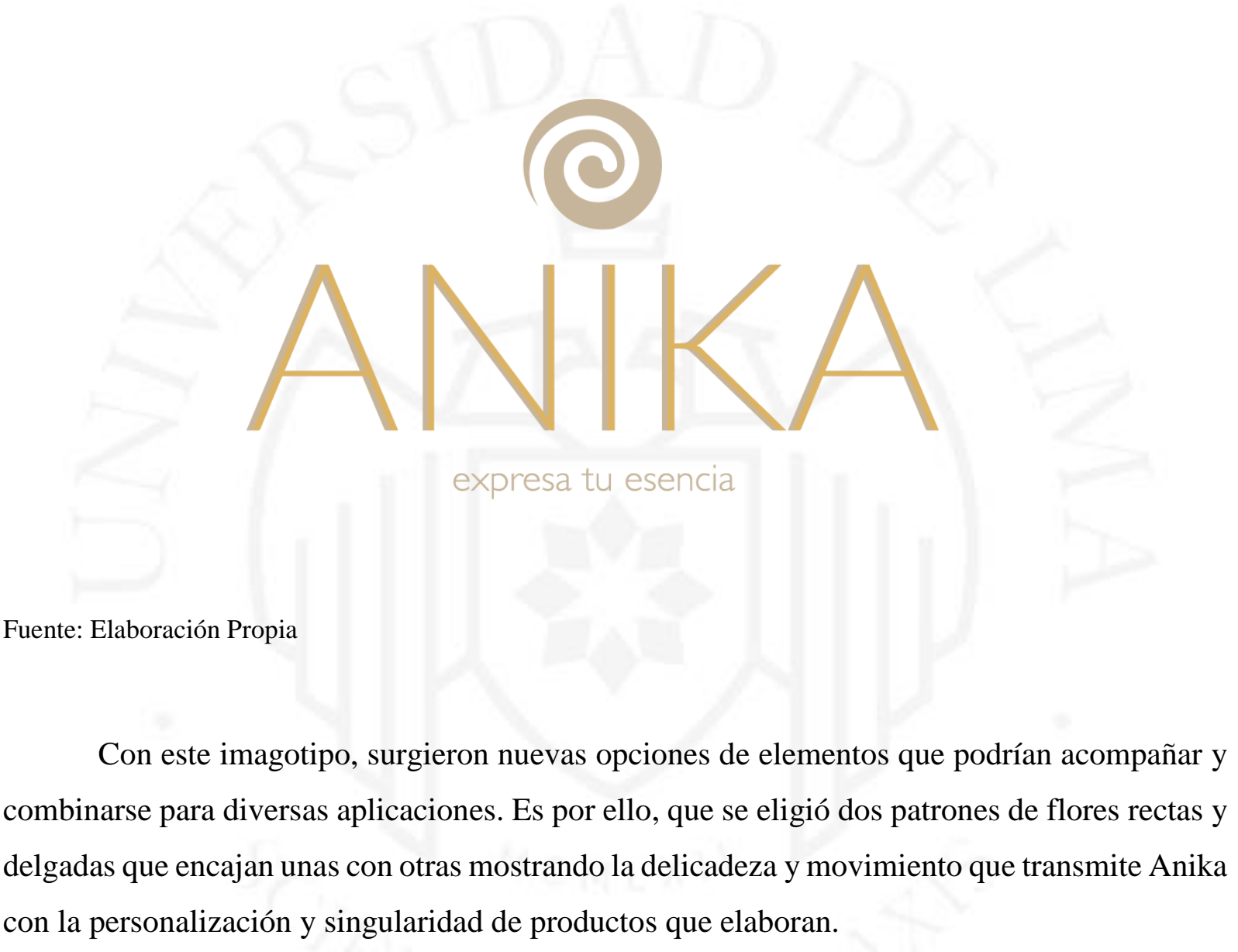


Imagen 1.9 Patrones de Anika

Fuente: Freepik

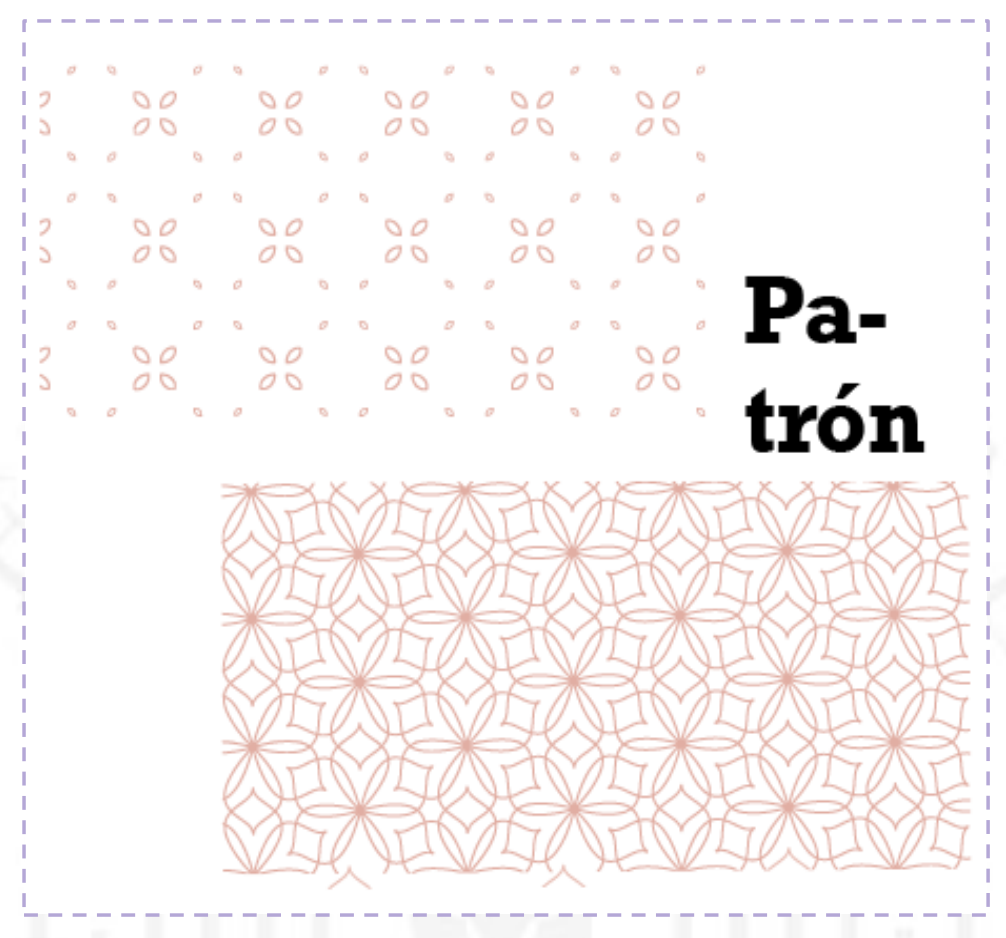

El contenido del manual se divide en cuatro bloques: la marca, identidad visual, entorno digital y elementos de identificación. En el primero, se describe información general de marca, como el origen, propósito, promesa, público objetivo, personalidad, entre otros; el segundo, incluye la identidad visual con el isotipo, imagotipo, pantone, tipografía, etc.; el tercero, comprende el tono de voz y ejemplos en el entorno digital, y el cuarto, por último, elementos de identificación de Anika como tarjetas de presentación, bolsas de regalos, entre otras aplicaciones. 


\subsection{Acciones en Facebook}

\section{https://www.facebook.com/anika.joyas/}

La página de Facebook de Anika cuenta con 620 seguidores y tiene publicaciones ocasionales (cada tres semanas). Por esta razón se plantea actualizar la página con la nueva identidad visual y proponer una comunicación más clara y continua con los usuarios ya que estos buscan contar con un contenido actualizado y detallado.

Para empezar, se actualizará la página con el nuevo logo y la línea gráfica de Anika (imagen de perfil y portada). Por otro lado, publicar algunos posts fotográficos de las colecciones ya fotografiadas.

Imagen 2.1 Portada Facebook de Anika
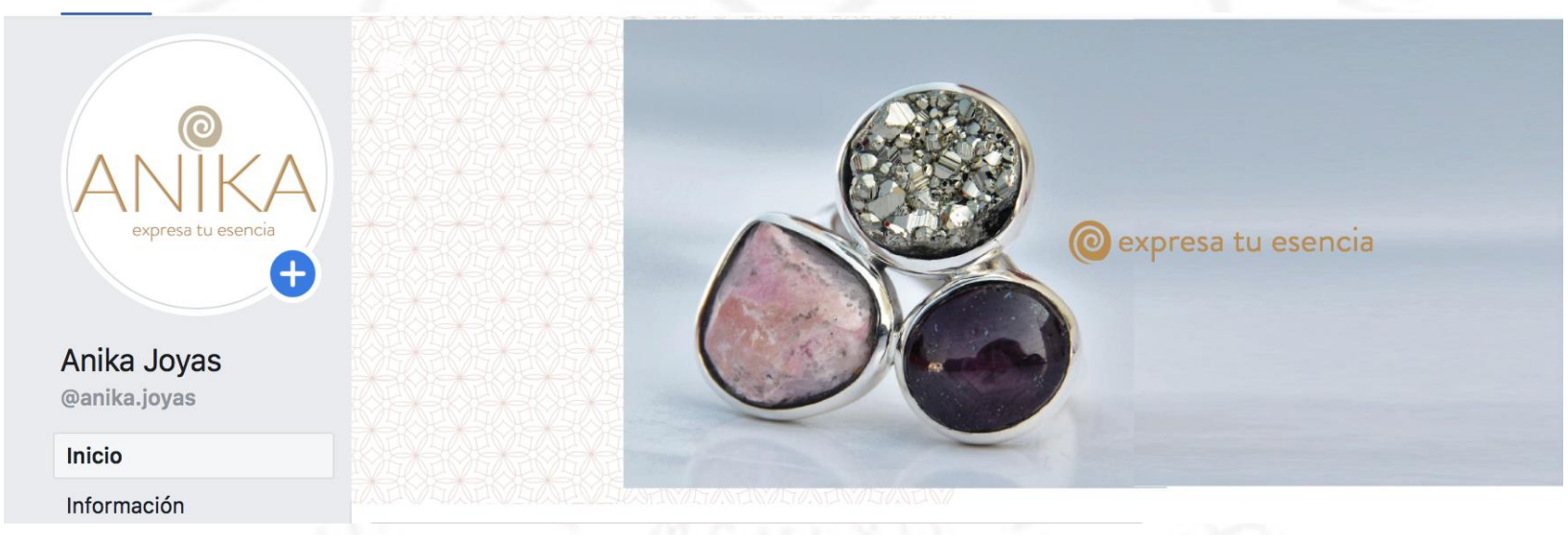

Fuente: Elaboración Propia 
Imagen 2.2 Ejemplo publicación - Facebook Anika

$$
\text { Anika Joyas }
$$
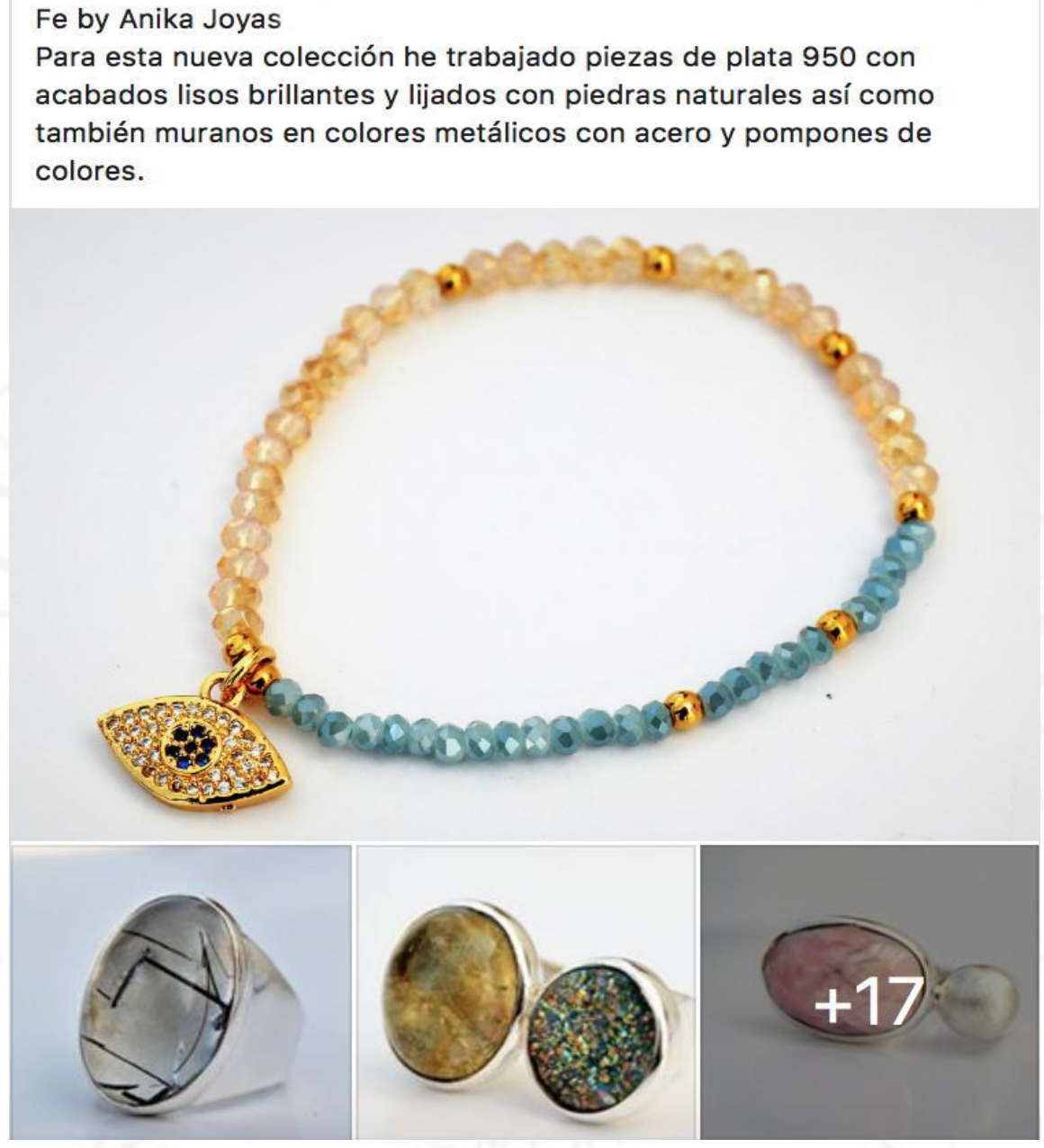

Fuente: Elaboración Propia

El indicador a evaluar en la página Facebook será la cantidad de seguidores y tasa de interacción y se pretende crecer a 1000 seguidores en 6 meses a través de publicaciones más recurrentes y con alianzas de otras marcas. 


\subsection{Resultados de validación}

\subsubsection{Comentarios de José Contto (Docente)}

$\square$ En términos de técnica fotográfica, se sugiere hacer uso de un lente teleobjetivo para obtener un mayor detalle de las fotos, así como también utilizar luz natural o equipos de luz para encontrar un fondo blanco adecuado para el catálogo de fotos.

- Si la temática de la sesión se sitúa en un entorno natural, se debe considerar poner las joyas en un espacio que haga referencia a este e implementar objetos como hojas grandes, troncos, etc.

$\square$ En el catálogo del producto se deben mostrar las joyas individuales y a su vez imágenes con modelos en situaciones que el público objetivo y potencial podría encontrarse como por ejemplo, estar en el celular, tener una cartera como accesorios, entre otros, para demostrar un sentido de asociación.

\subsubsection{Comentarios de Alessandra Baldoceda (Diseñadora Gráfica)}

$\square$ Sobre el manual, se recomienda separar los contenidos para maximizar el espacio de la hoja, es decir, colocar los títulos en tamaño grande que ocupen la mesa de trabajo y en la siguiente, ingresar el cuerpo de texto correspondiente. Con ello, los títulos y cuerpo de texto se podrán apreciar mejor y generarán mayor impacto en la lectura.

$\square$ El pantone de colores pasteles es agradable y se complementan entre sí; sin embargo, se sugiere incorporar un color frío (similar al guinda) para que rompa con el contraste previo y tenga mayor impacto visual.

En cuanto a los patrones, se recomienda considerar un patrón que se asemeje al isotipo de Anika (espiral) para tener una vista más suave y genere recordación con el elemento principal.

$\square$ En la sección de elementos de identificación se consideran propuestas de empaque, papelería, firma electrónica, etc. Si bien se muestra el diseño, se debería incluir mock up, modelo a escala, para que sea más real y se aprecie mejor el arte trabajado. 


\subsubsection{Comentarios de Angie Ballón (Cliente)}

$\square$ El espiral de Anika es la base de la identidad de la marca y debe aparecer constantemente en el diseño del manual así como dentro de las fotografías.

- La actualización del logotipo ha modernizado la imagen de Anika y se alinea con lo que busca como fundadora de la Anika. Los colores similares a un "tierra" e "ivory" deben ser conservados ya que son reconocidos por sus clientes, y agregar los colores pasteles de los empaques donde se entregan las joyas refuerza la línea gráfica de la marca.

$\square$ Las imágenes de las sesiones son clave para la marca ya que es necesario comunicar los nuevos productos y colecciones; sin embargo, las imágenes para el catálogo deberían ser tomadas en un estudio con mayor iluminación para obtener una fotografía más limpia. 


\section{CAPÍTULO III: LECCIONES APRENDIDAS}

El objetivo de este proyecto fue reforzar el posicionamiento de la identidad de Anika, basándose en los atributos de la misma. Para ello, se tomó la decisión de reconstruir el imagotipo y sus elementos principales, incorporando estos cambios en un manual de marca. Con el brandbook, se definieron los lineamientos de la marca para generar una comunicación integrada en todos sus medios de comunicación.

En mi opinión, en la elaboración de un proyecto es fundamental realizar investigación constante sobre el tema. En este caso, conocer el negocio de las joyas, el proceso de producción y conversar con los propios clientes, permitió tener claro qué es lo que la marca necesitaba y cuál sería el rol que cumpliría y aporte en este proyecto.

Asimismo, estar en contacto constante con el cliente permitió forjar una relación cercana con él y entender con precisión lo que necesitaba a través de insights que se fueron reconociendo en el camino. Por lo tanto, construir una relación con el cliente tiene un valor agregado esencial que contribuye a obtener información de primera mano para el desarrollo del proyecto

Por otro lado, luego de reconstruir el imagotipo de Anika se cree que diseñar un isotipo es un trabajo perceptivo y cumple con las cualidades propias de un trabajo estético, pero a nivel profesional, se aprendió que la sistematización geométrica, refuerza el concepto de mantener una estructura constante y sin variaciones en las aplicaciones de la marca a lo largo del tiempo.

Cabe mencionar que la validación de expertos y cliente tuvieron un rol importante ya que generaron cambios esenciales para el desarrollo del proyecto. Por ejemplo, corregir la técnica fotográfica y agregar otros elementos referentes a la naturaleza mejoraron la composición de las imágenes; por otro lado, seleccionar el pantone complementario y dos tipografías fueron recursos importantes para el diseño del manual. Con la combinación de ambos se obtuvo un diseño más armónico y moderno. 
Asimismo, se consultó al experto en diseño y al cliente si el proyecto entregado cumplía con el objetivo trazado. El experto opinó que el brandbook consideraba todos los puntos importantes y básicos para la reconstrucción de un logotipo y los lineamientos de una marca y que con este material, el cliente podría generar una estrategia de comunicación exitosa en resultados.

En cuanto al cliente, éste comentó que este proceso le ha ayudado a definir su marca y tener una orientación más clara de lo que propone para los próximos años. También afirmó que el material propuesto contribuye al crecimiento de la marca ya que no contaba con esto anteriormente y era solicitado por clientes corporativos y sugirió que se considere diseñar otras piezas como brochure o merchandising.

Luego de saber las opiniones del cliente y experto, se puede concluir que este trabajo cumplió con su objetivo y servirá de aplicación para la marca; asimismo, se espera que sea considerado como modelo de referencia en cuanto al tipo de contenido a considerar y los pasos a seguir para estructurar un brandbook. Además, se espera que se tome en cuenta la inclusión de otros materiales aparte del diseño como fotografías, videos, gifs, entre otros, para hacer un proyecto más completo.

Elaborar un brandbook y producir material, en este caso las fotografías de joyas, desde cero permite generar propuestas y enseñar al cliente lo importante que es tener los lineamientos de su marca para cualquier situación. Por ende, considero que este trabajo puede servir para los comunicadores que quieran hacer un proyecto similar con una marca emprendedora que se encuentre en desarrollo ya que con ello, pondrán en práctica los conocimientos aprendidos y asimismo, guiarán a sus clientes a saber cómo desarrollar una comunicación alineada a las características de sus marcas. 


\section{BIBLIOGRAFÍA}

Anika Joyas. (s.f). Acerca de [página de Facebook] Recuperado el 22 de marzo del 2019 de Facebook: https://www.facebook.com/pg/anika.joyas/about/?ref=page_internal

Perú: Ventas del sector joyería al exterior sumarían US\$ 148 millones a fines del 2019 (2019, 26 de noviembre) Recuperado del sitio de internet de Perú Retail: https://www.peruretail.com/peru-ventas-del-sector-joyeria-al-exterior-sumarian-us-148-millones-afines-del-2019/

La evolución de la mujer peruana (2019). Recuperado el 23 de enero del 2020 de Arellano Marketing website: https://www.arellano.pe/la-evolucion-de-la-mujer-peruana/

Los seis Estilos de Vida (s.f). Recuperado el 23 de enero del 2020 de Arellano Marketing website: https://www.arellano.pe/los-seis-estilos-de-vida/

Claudia Navarro Jewerly (s.f). Inicio [página de Facebook] Recuperado el 18 de febrero del 2020 de Facebook: https://www.facebook.com/claudianavarrojewelry

Petunia (s.f). Inicio [página de Facebook] Recuperado el 17 de febrero del 2020 de Facebook: https://www.facebook.com/Petunia.com.pe/

Petunia [@ petunialovers] (s.f). Posts [perfil de Instagram] Recuperado el 17 de febrero del 2020 de Facebook: https://www.facebook.com/Petunia.com.pe/

La Perica Joya (s.f). Inicio [página de Facebook] Recuperado el 17 de febrero del 2020 de Facebook: https://www.facebook.com/Petunia.com.pe/

Poke Studio (2020). Chit Par Jewerly. Recuperado el 10 de febrero del 2020 de Behance website:

https://www.behance.net/gallery/90100689/Chit-ParJewelry?tracking source=search\%7CJEWELRY\%20BRANDBOOK 
Tatyana Ipatova (2020). Lilkin's Handmade Jewerly. Recuperado del sitio de internet de Behance: $\quad$ https://www.behance.net/gallery/91668315/Lilkins-handmadejewelry?tracking source=search\%7CJEWELRY\%20BRANDBOOK

Izabel Camille Jewerly (2019). Izabel Camille Jewerly Brandbook. Recuperado del sitio de internet de Issuu: https://issuu.com/izabelcamillejewelry/docs/brandbook_izabel_camille_jewelry

Studio Standard (2017). Portobello - Guidelines. Recuperado del sitio de internet de Behance:: https://www.behance.net/gallery/53933177/Portobello-Guidelines

Egotype (2017). Purism Brand Manual - Guidelines. Recuperado del sitio de internet de Behance: $\quad$ https://www.behance.net/gallery/58234761/Purism-Brand-ManualGuidelines

October Ink. (s.f.). How to use patterns in your Branding - October Ink. Recuperado del sitio de internet de October Ink: http://octoberink.com/how-to-use-patterns-in-branding/ 
ANEXOS 


\section{Anexo 1: Behance Chit Par Jewerly}

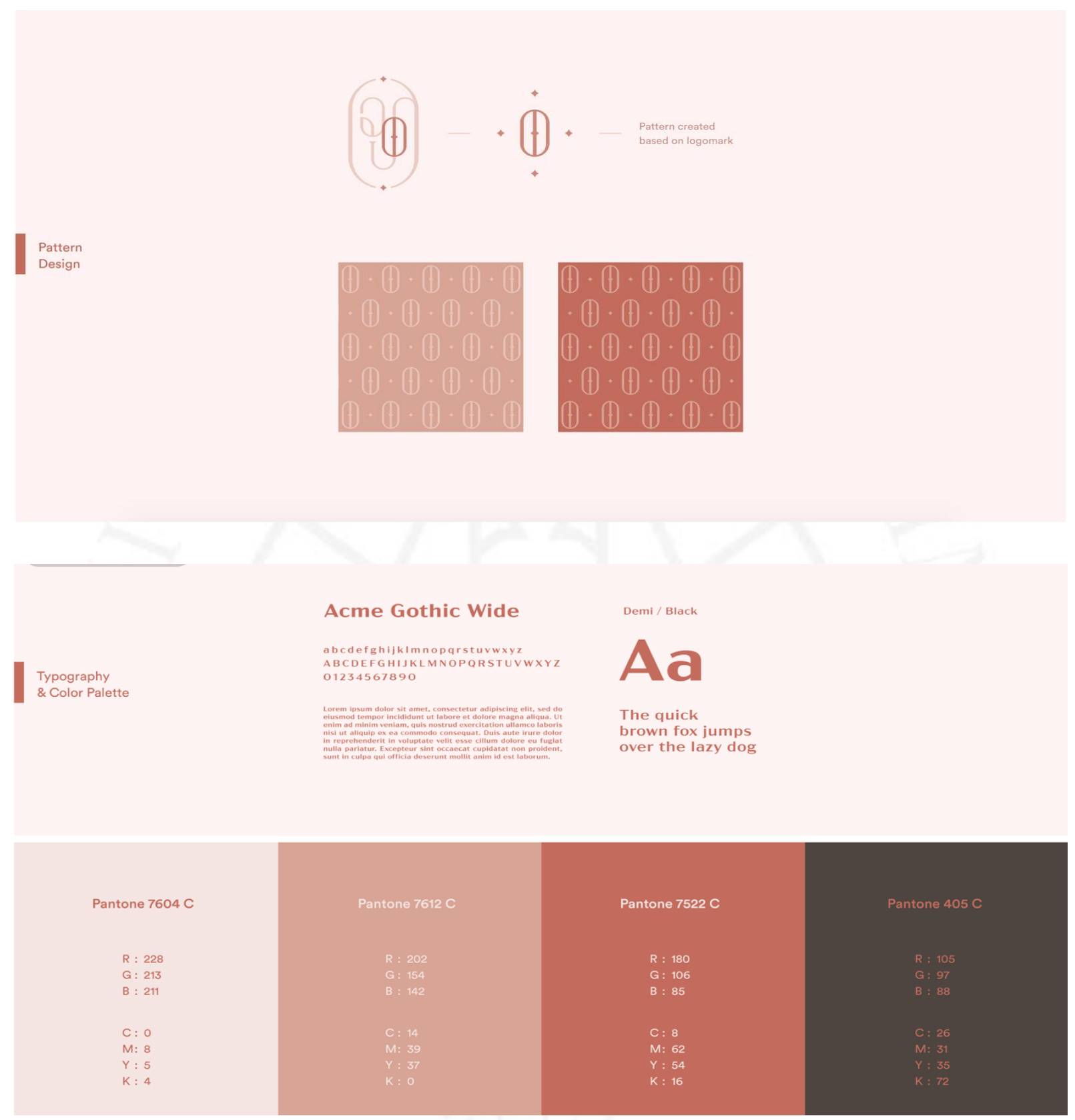




\section{Anexo 2: Behance Lilkin's Handmade Jewerly}

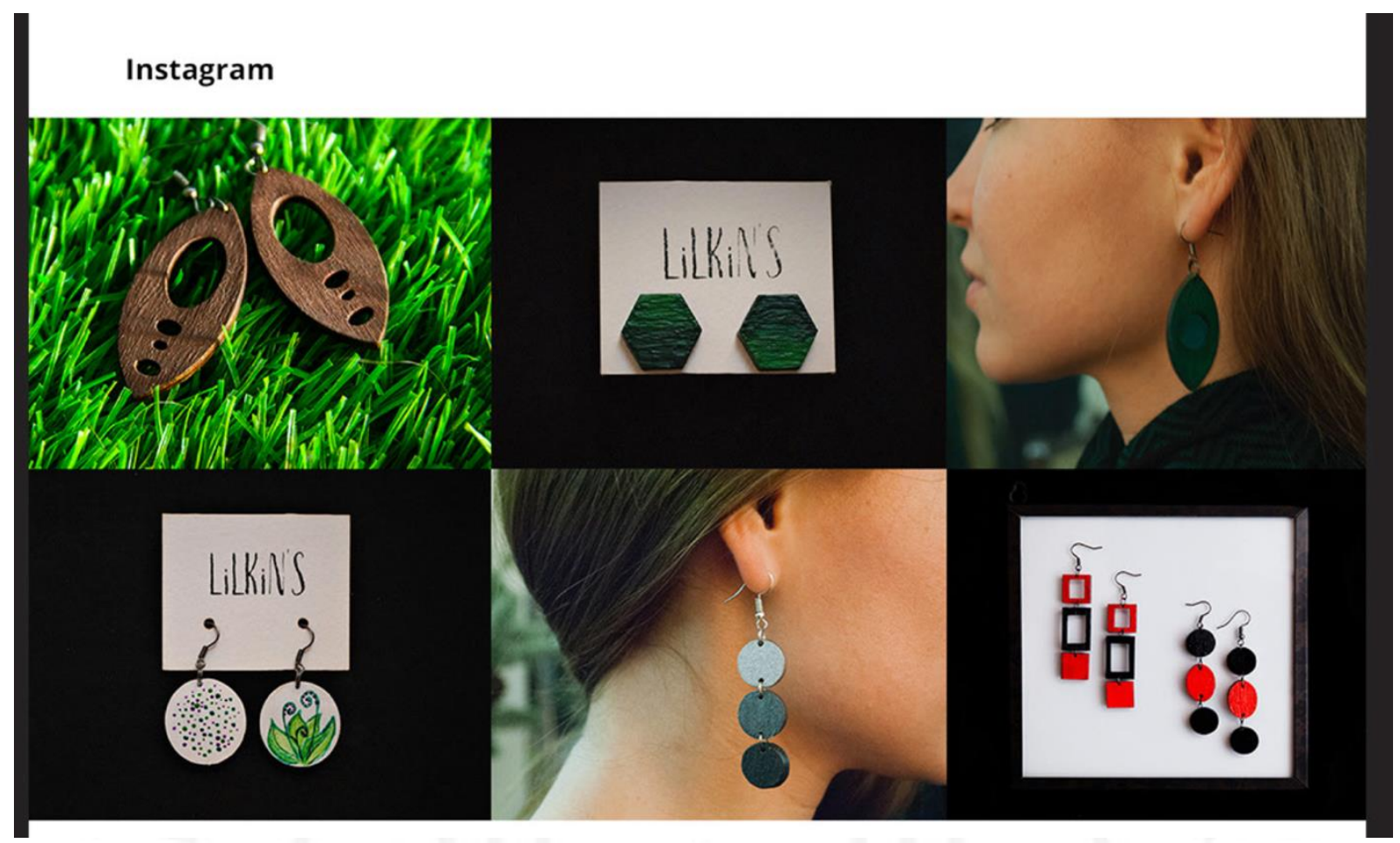

\section{О проекте \\ About project}

Перед вами дизайн сайта дизайнерских, уникальных

украшений, сделанных вручнуо.

Главная задача-показать минималистичность

и уникальнось бренда.

\section{$\longrightarrow$}

Here is a design of the site design, unique handmade jewely. The main task is to show minimallism and brand uniqueness.
Анализ и решение Analysis and solution

Были проанализированы сайты конкурентов.

В ходе создания дизайна сайта было принято решение

придерживаться спокойного и выдержанного стиля.

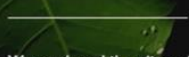

We analyzed the sites of competitors. During the creation of the site design the decision to stay calm and seasoned style. 


\section{Anexo 3: Brandbook Izabela Camille Jewerly - Issuu}
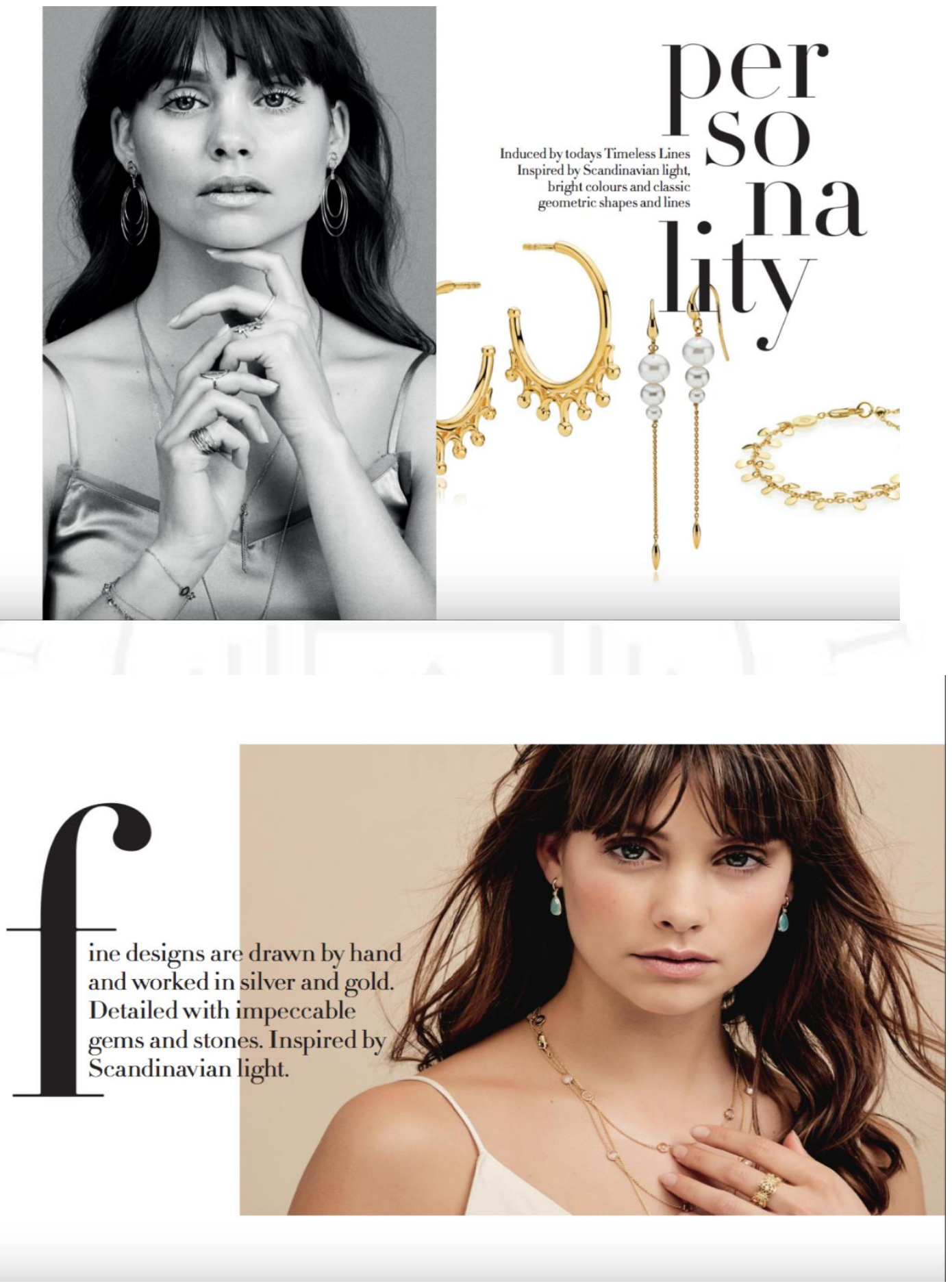


\section{Anexo 4: Facebook de Claudia Navarro}

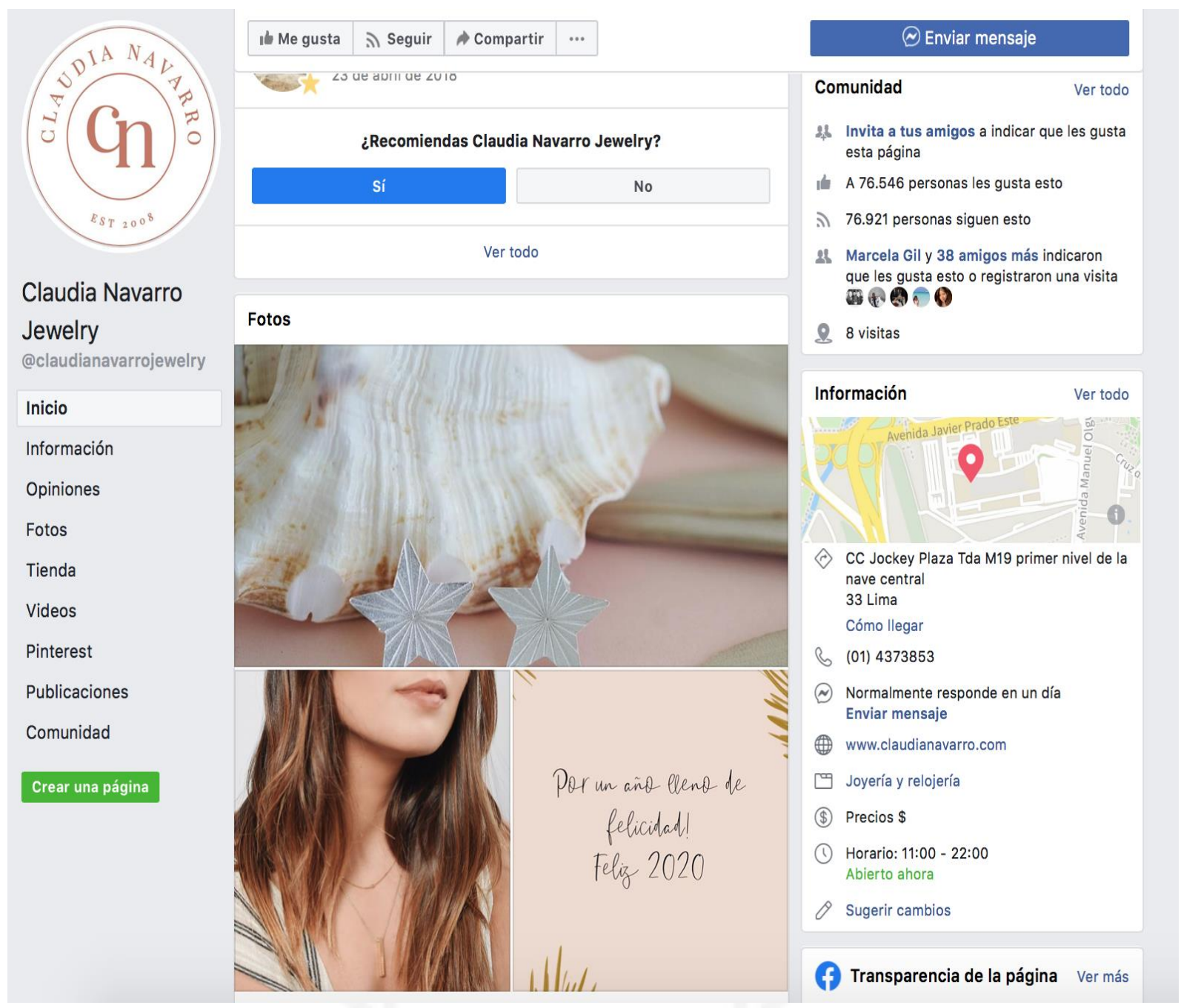




\section{Anexo 5: Post Facebook de Claudia Navarro}

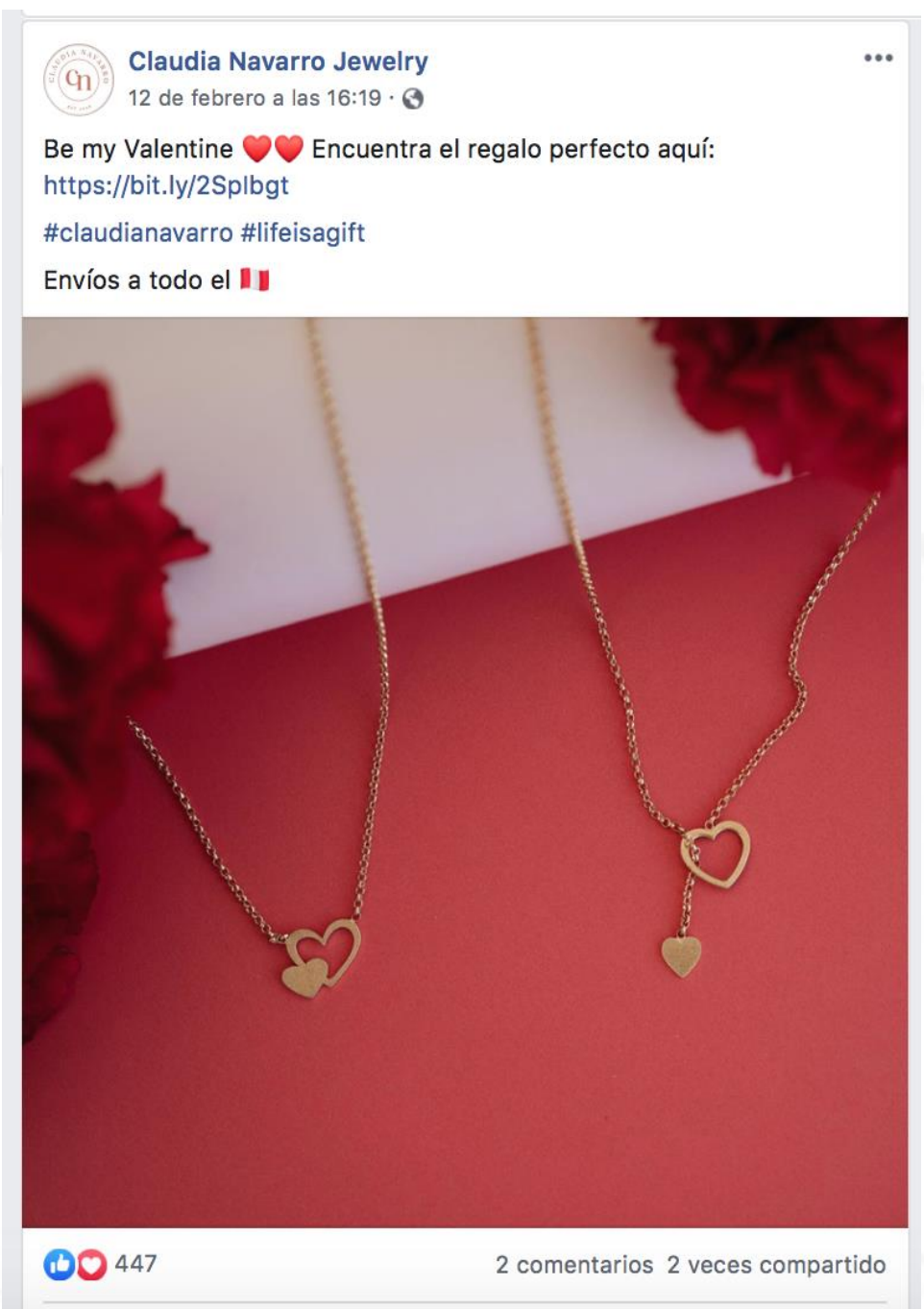




\section{Anexo 6: Página web de Claudia Navarro}

208 resultados Ordenar por: $\quad$ Ordenar $A-Z \quad \sim$

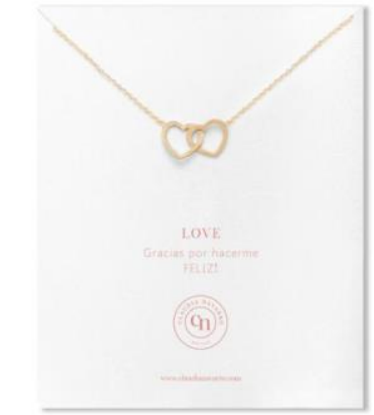

Collar 2 Corazones Gold

S/. 129.00

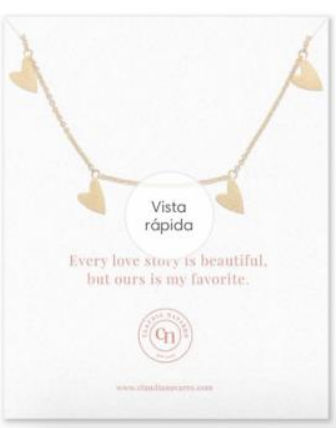

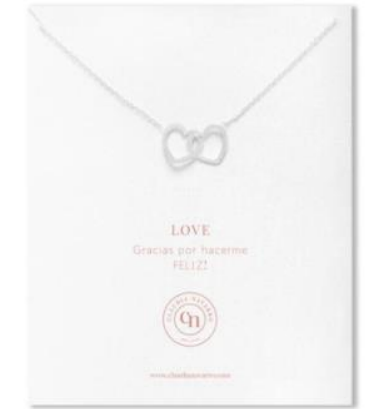

Collar 2 Corazones Silver

S/. 119.00

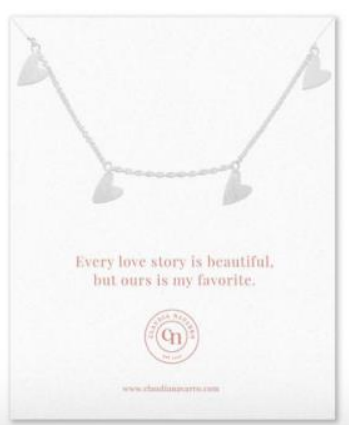

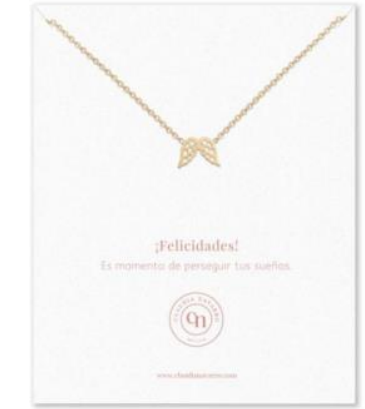

Collar Alitas Gold

S/. 129.00

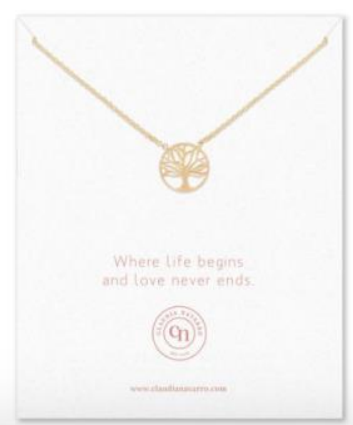

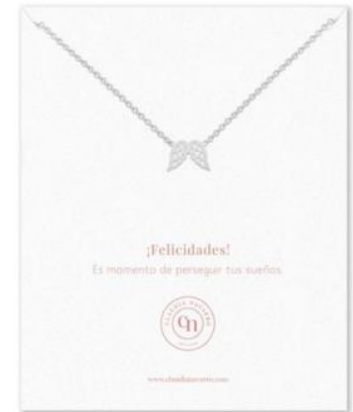

Collar Alitas Silver

S/. 119.00

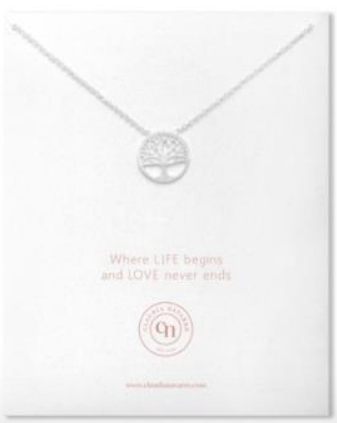




\section{Anexo 7: Facebook de Petunia}

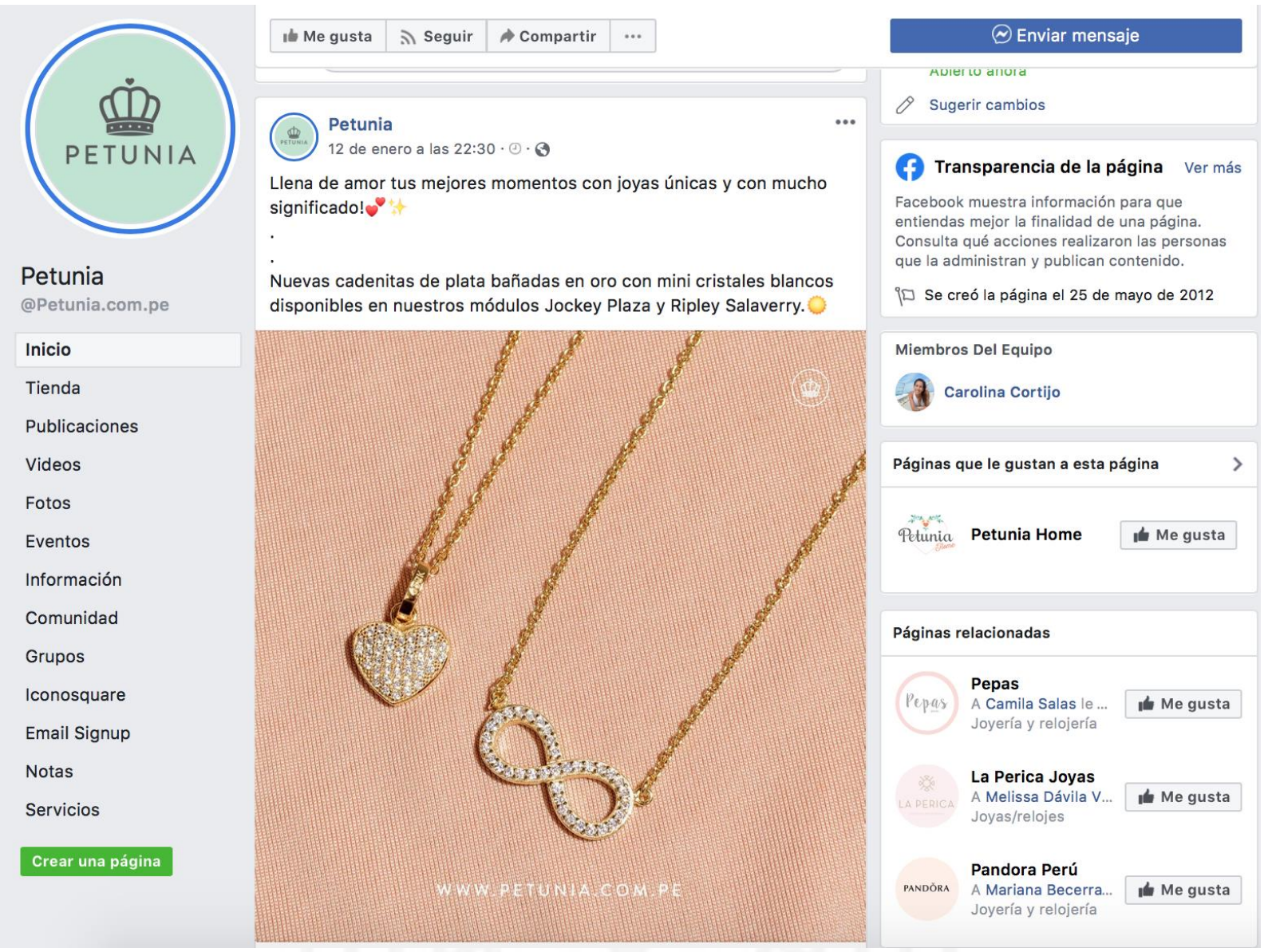




\section{Anexo 8: Instagram de Petunia}

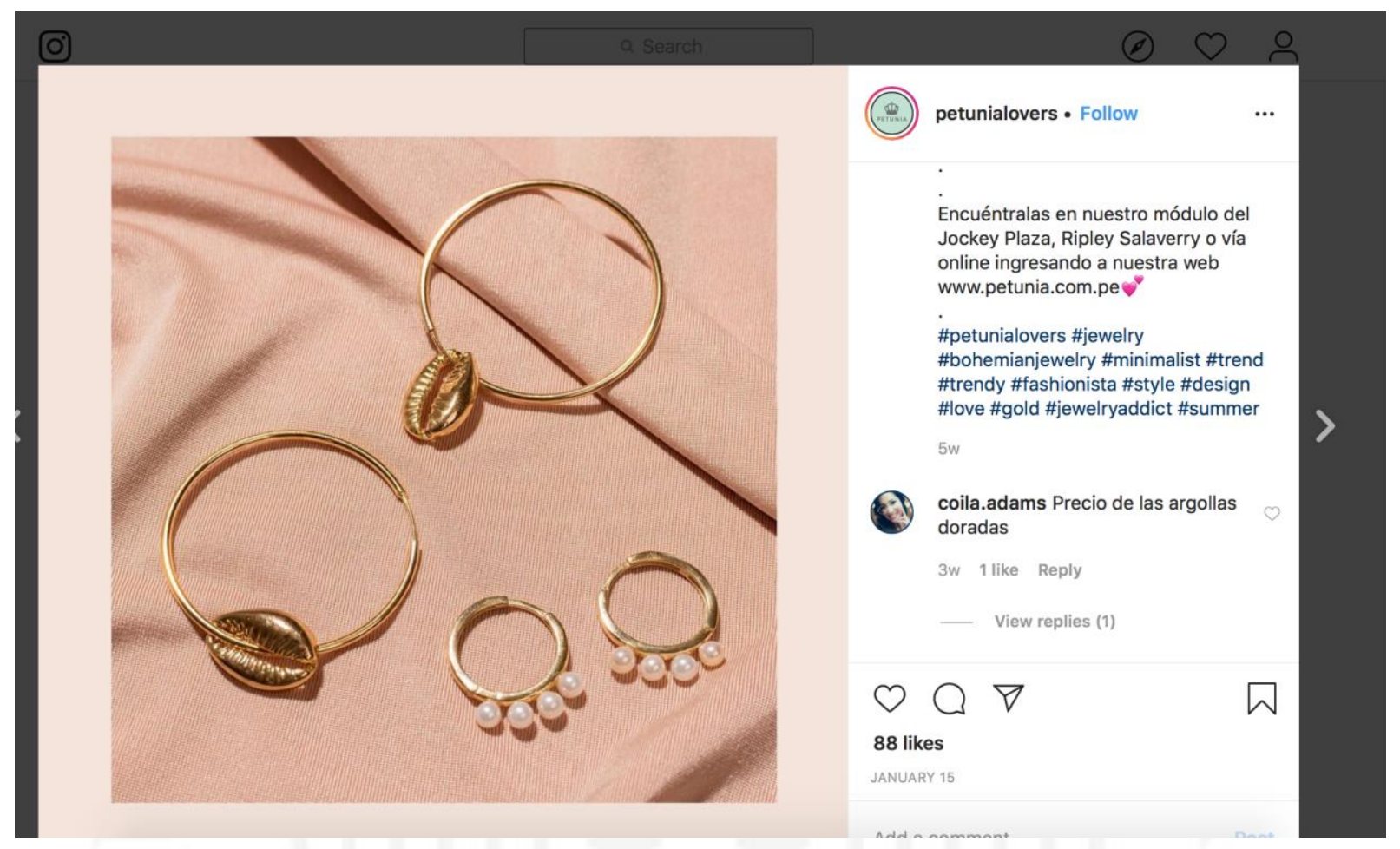




\section{Anexo 9: Página web de Petunia}

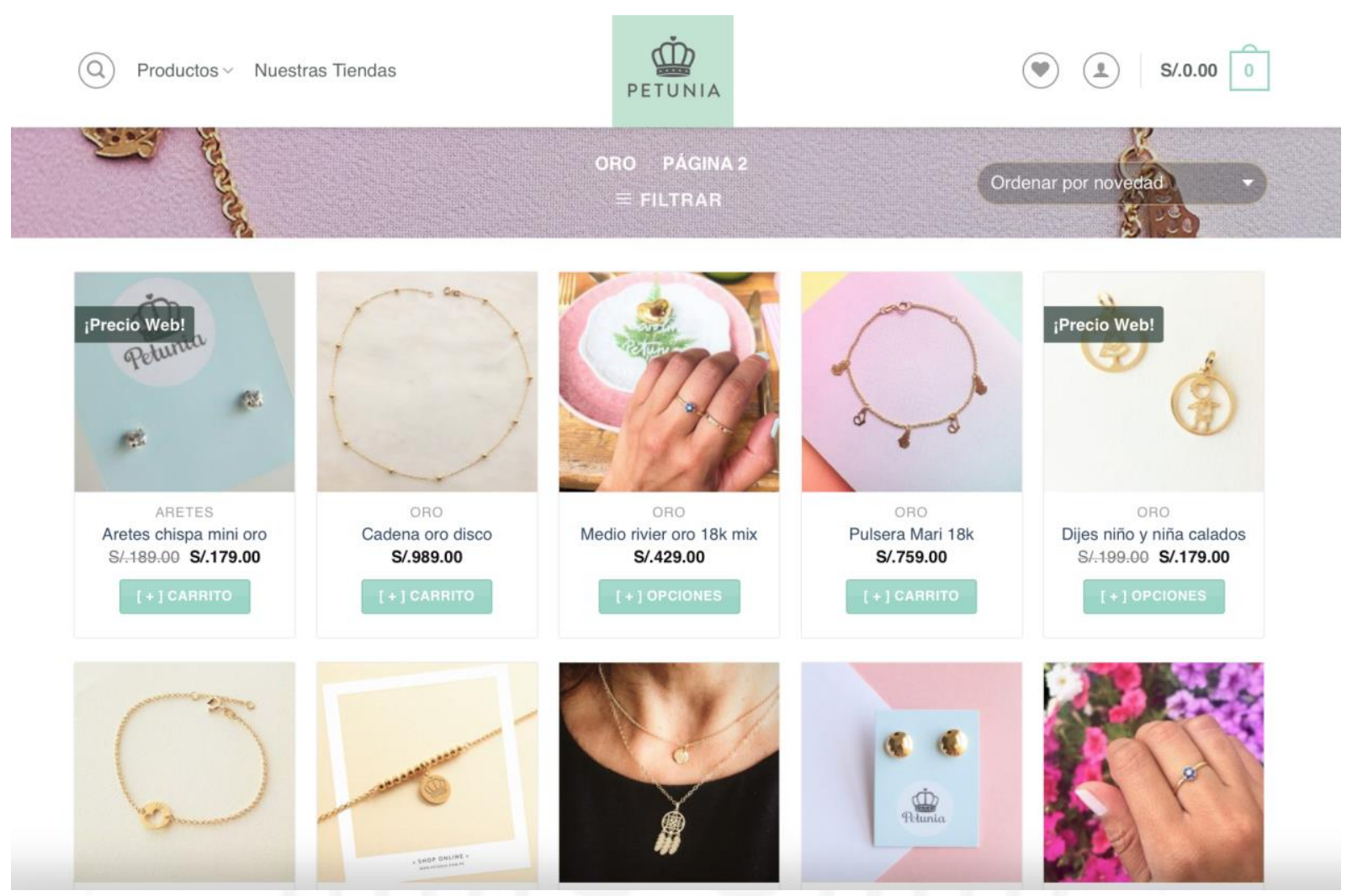




\section{Anexo 10: Productos en página web de Petunia}

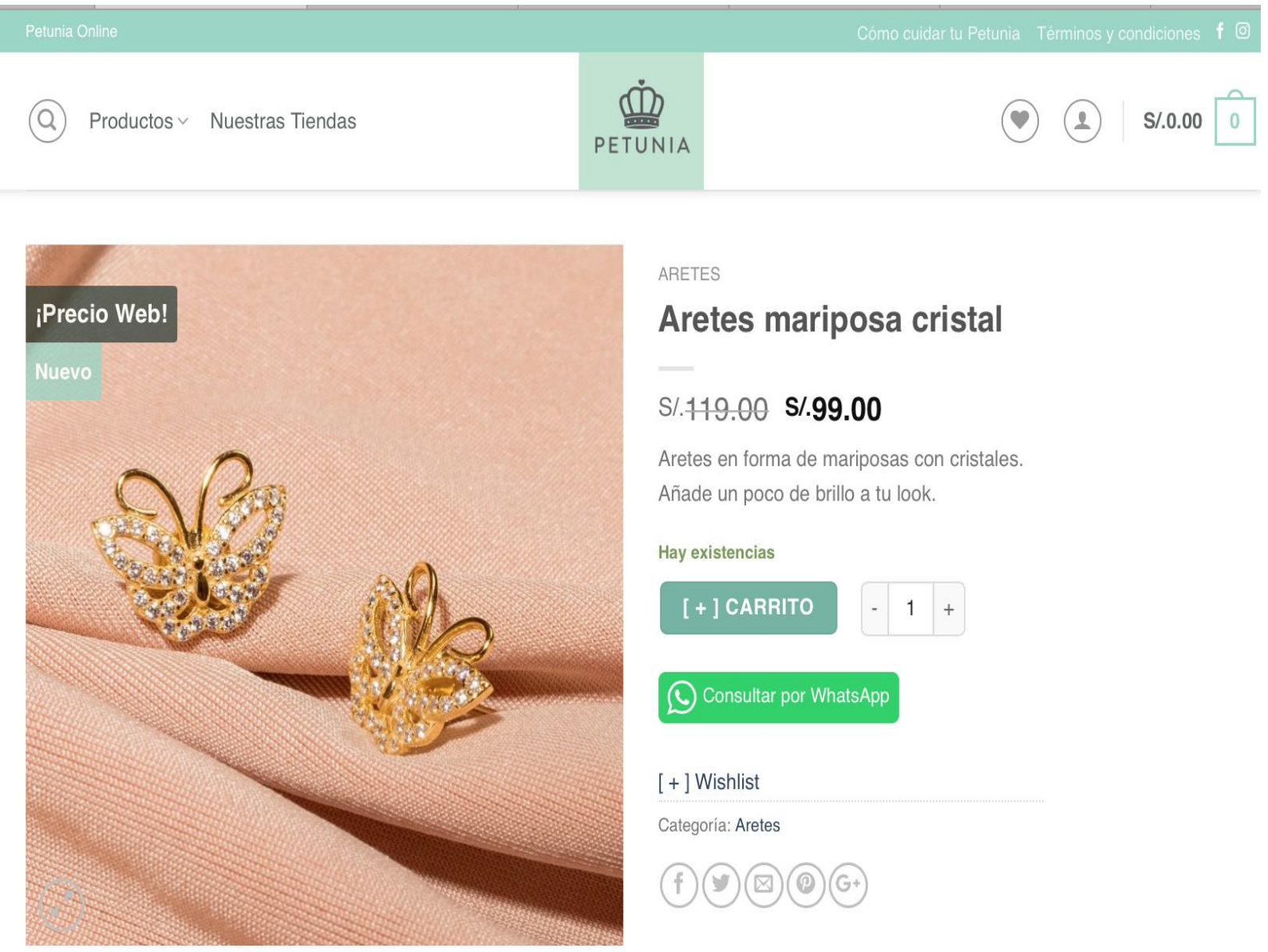




\section{Anexo 11: Tienda Facebook de La Perica}

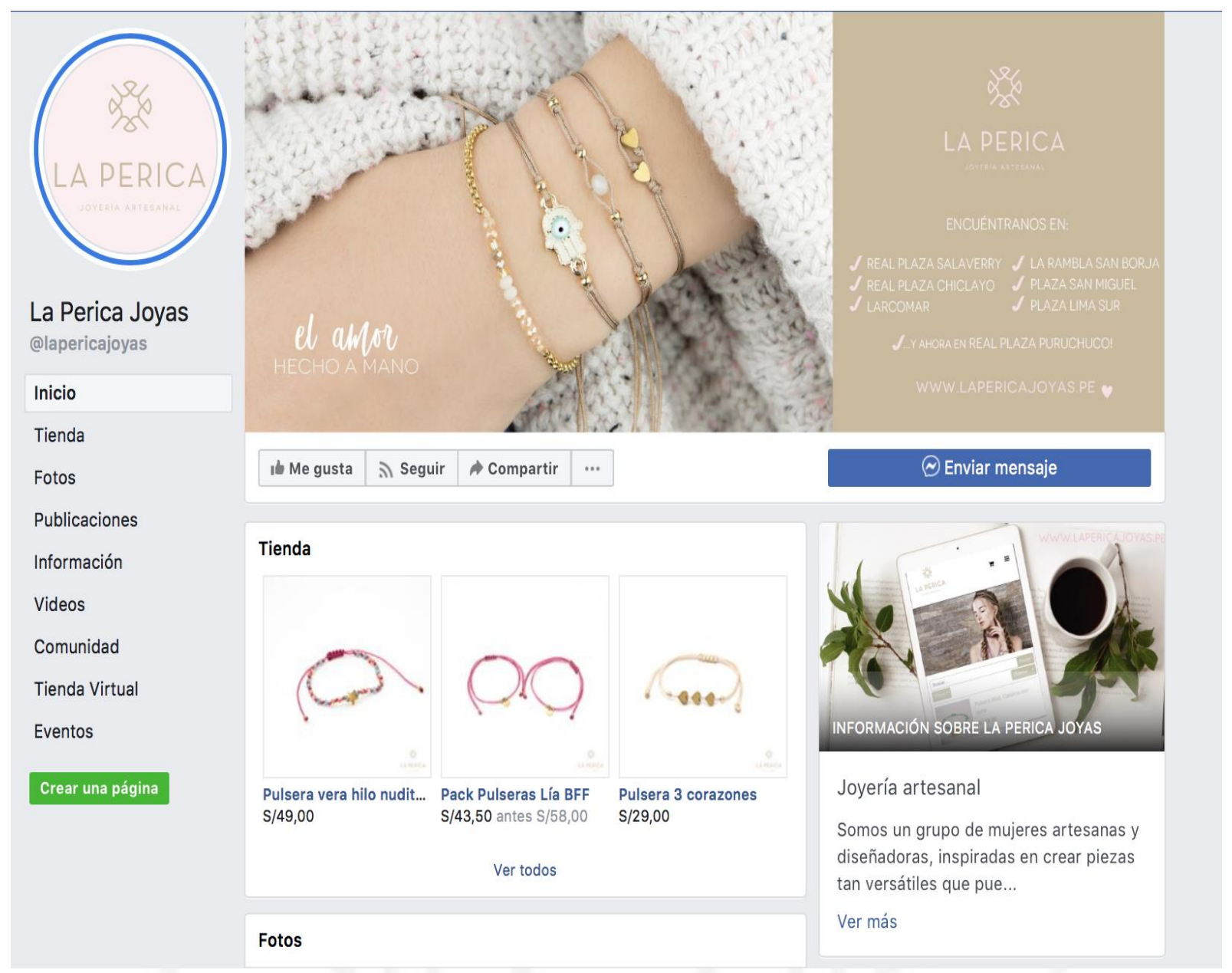




\section{Anexo 12: Facebook de La Perica}

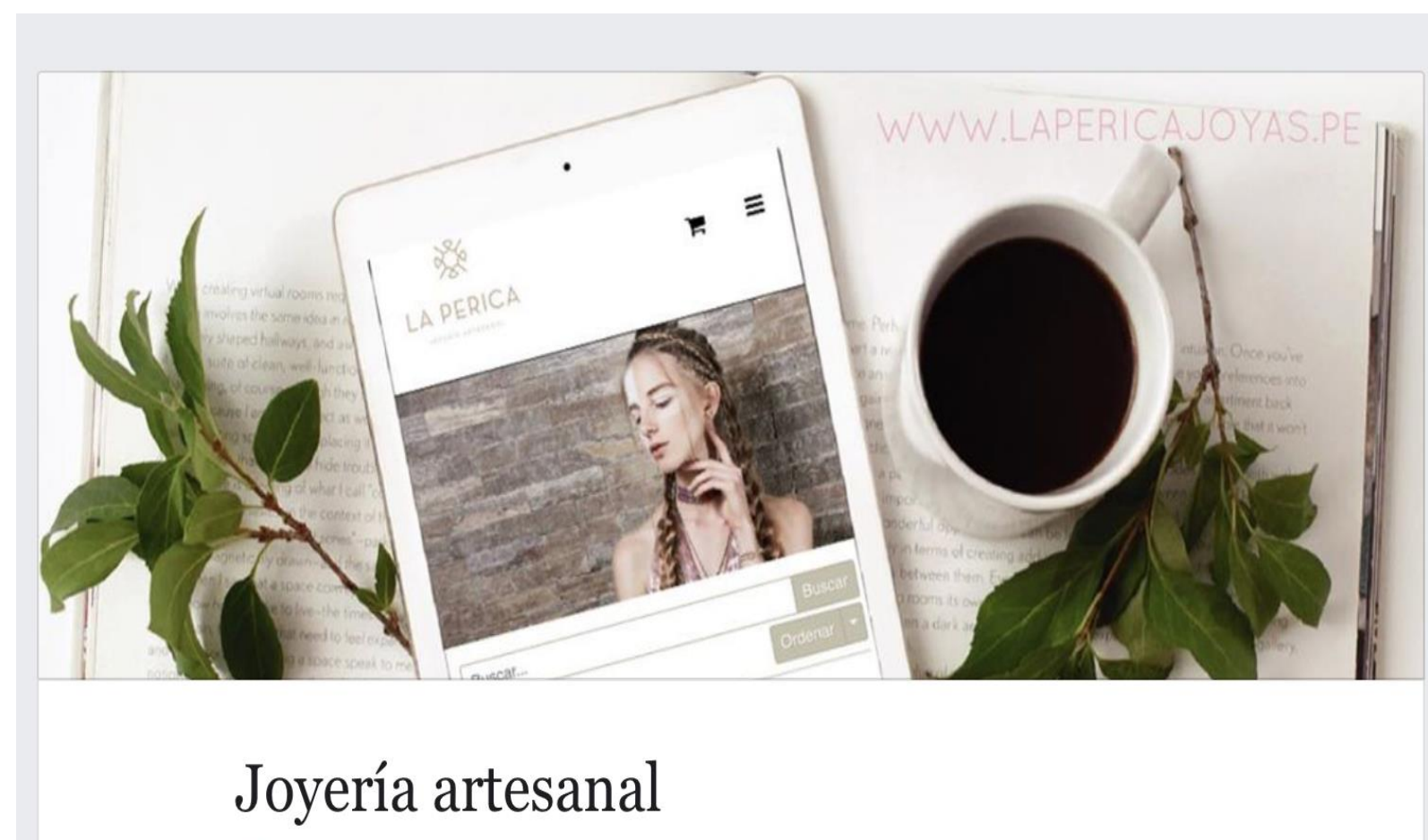

LA PERICA JOYAS · MARTES, 5 DE JUNIO DE 2018

Somos un grupo de mujeres artesanas y diseñadoras, inspiradas en crear piezas tan versátiles que puedan ser usadas por todo tipo de mujer. 


\title{
Anexo 13: Página web de La Perica
}

\author{
RELIGIOSA ( 12) \\ COLECCIÓN ROSE \\ GOLD (4) \\ COLECCION SILVER \\ GOLD (152) \\ - Aretes Silver Gold ( 72 \\ - Collares Silver Gold \\ (76) \\ - Pulseras Silver Gold \\ (4) \\ COLLARES (73) \\ - Acero Quirúrgico (31) \\ - Collares Largest (4) \\ - Cobre (59) \\ DIJES ( 9 ) \\ HOLDER PARA \\ LENTES (3) \\ PACKS (67) \\ - Packs de Pulseras ( 56 \\ - Packs de Regalo (10) \\ PULSERAS ( 80 ) \\ Pulsera Catalina
}
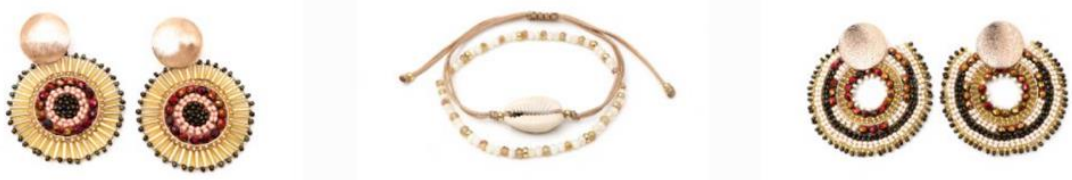

Maxiaretes Nicole

Pack Pulseras $\times 2$ Caracol

Maxiaretes Cleo

S/. 59.00

S/. 39.00

S/. 75.00

Ver más

Ver más

Ver más
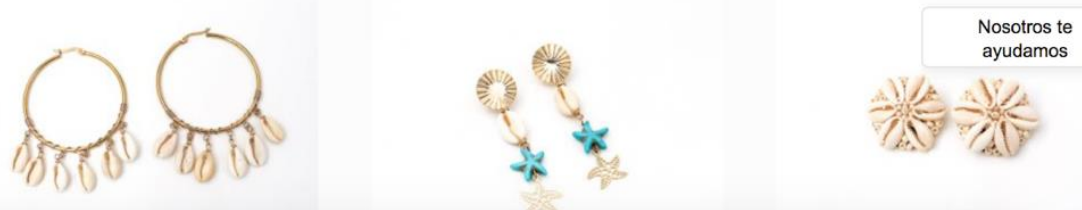


\section{Anexo 14: Página web de Pandora}

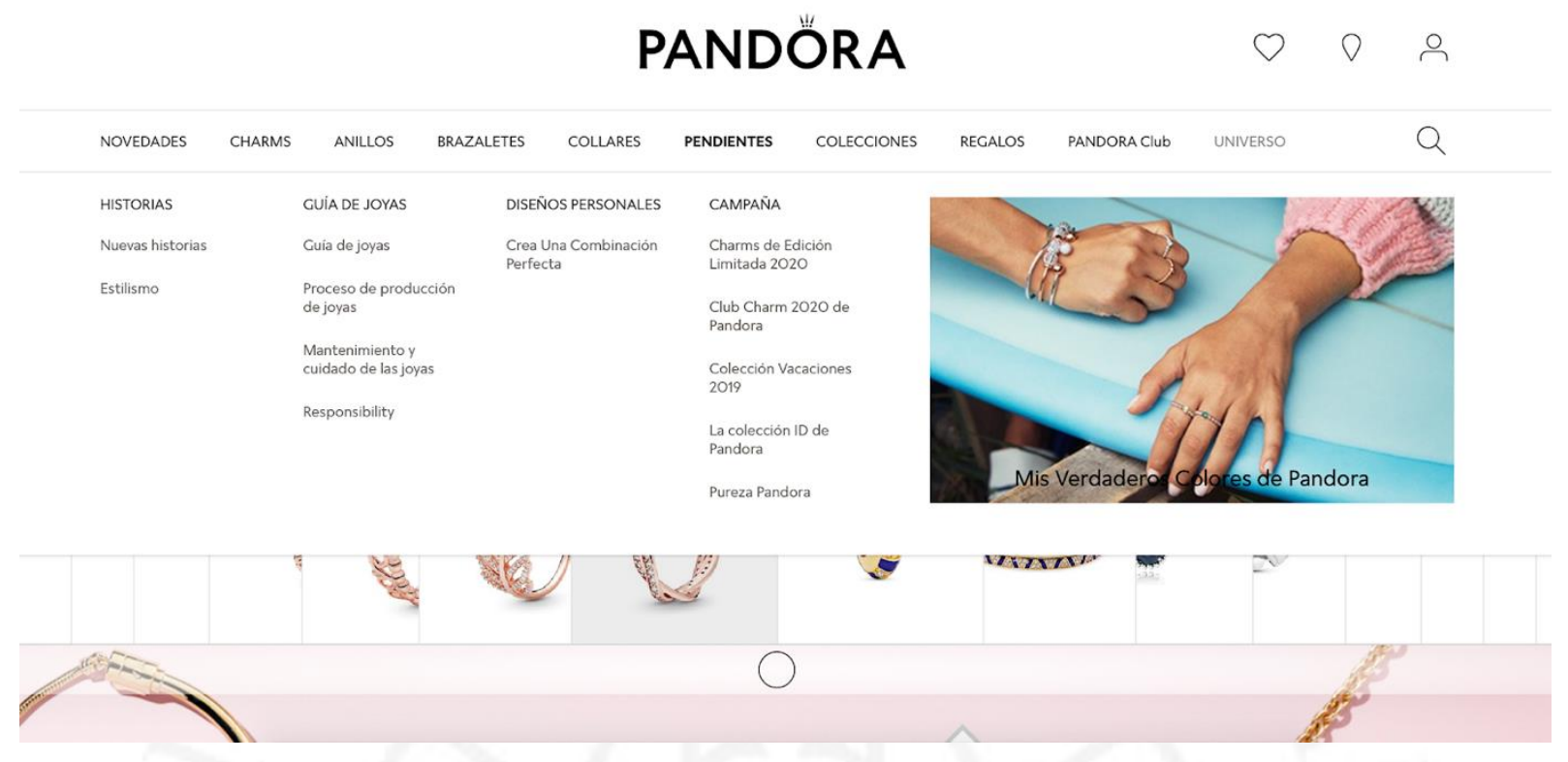




\section{Anexo 14: Página web de Pandora}

\section{Pandora}

12 de febrero a las $17: 30 \cdot 6$

Celebremos en este Día del Amor y de la Amistad, desde el amor propio hasta los lazos inquebrantables de la familia.

\#DemuéstraleQueLaConoces \#PandoraValentine \#SanValentin \#Pandora

¡Visita tu tienda Pandora y conoce esta nueva colección 2020! Conoce nuestra catálogo: https://bit.ly/2uMBBqX

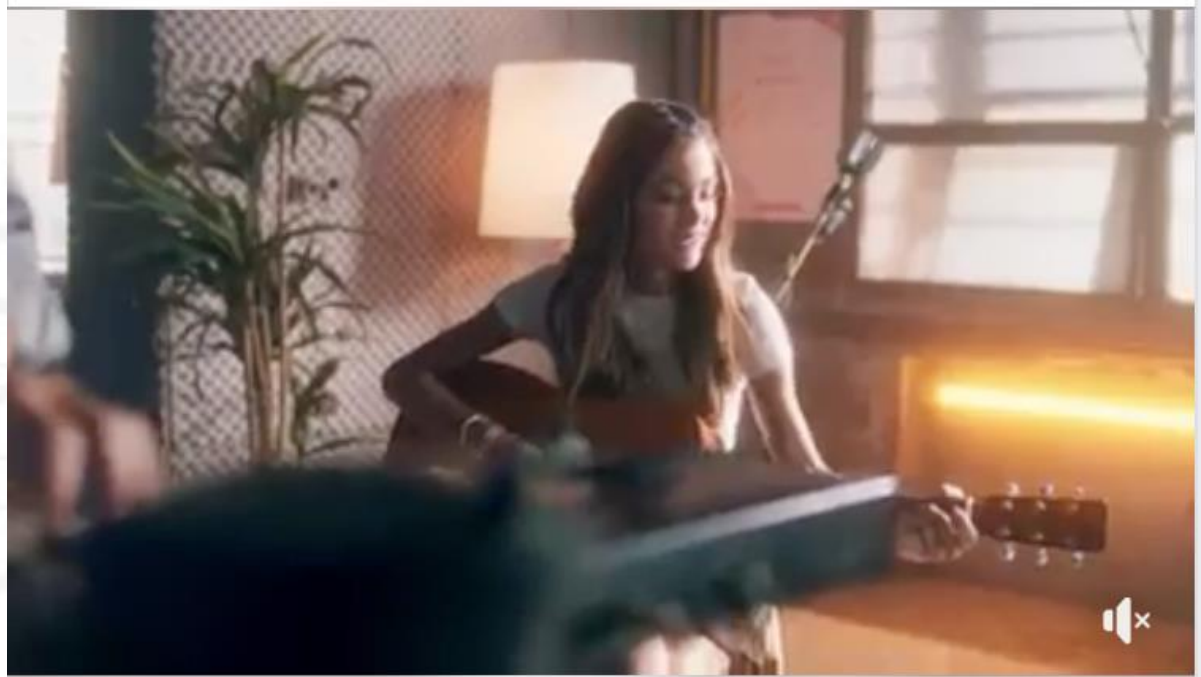

27 comentarios 88 veces compartido

(3) gusta

Comentar

$\phi$ Compartir 